\title{
Drugs That Modify Cholesterol Metabolism Alter the p38/JNK-Mediated Targeted and Nontargeted Response to Alpha and Auger Radioimmunotherapy
}

\author{
Riad Ladjohounlou', Catherine Lozza', Alexandre Pichard', Julie Constanzo', Jihad Karam', \\ Pierre Le Fur', Emmanuel Deshayes', Vincent Boudousq ${ }^{1}$, Salomé Paillas ${ }^{1}$, Muriel Busson', \\ Marion Le Blay', Marta Jarlier ${ }^{2}$, Sara Marcatili ${ }^{3}$, Manuel Bardiès ${ }^{3}$, Frank Bruchertseifer ${ }^{4}$, \\ Alfred Morgenstern ${ }^{4}$, Julien Torgue ${ }^{5}$, Isabelle Navarro-Teulon ${ }^{1}$, and Jean-Pierre Pouget ${ }^{1}$
}

\begin{abstract}
Purpose: For the development of new anticancer therapeutic radiopharmaceuticals, including alpha particle emitters, it is important to determine the contribution of targeted effects in irradiated cells, and also of nontargeted effects in nonirradiated neighboring cells, because they may affect the therapeutic efficacy and contribute to side effects.

Experimental Design: Here, we investigated the contribution of nontargeted cytotoxic and genotoxic effects in vitro and in vivo (in xenografted mice) during alpha $\left({ }^{212} \mathrm{~Pb} /{ }^{212} \mathrm{Bi},{ }^{213} \mathrm{Bi}\right)$ and Auger $\left({ }^{125} \mathrm{I}\right)$ radioimmunotherapy (RIT).

Results: Between 67\% and 94\% (alpha RIT) and 8\% and $15 \%$ (Auger RIT) of cancer cells were killed by targeted effects, whereas $7 \%$ to $36 \%$ (alpha RIT) and $27 \%$ to $29 \%$ (Auger RIT) of cells were killed by nontargeted effects. We then demonstrated that the nontargeted cell response to alpha and Auger

RIT was partly driven by lipid raft-mediated activation of p38 kinase and JNK. Reactive oxygen species also played a significant role in these nontargeted effects, as demonstrated by $\mathrm{NF}-\kappa \mathrm{B}$ activation and the inhibitory effects of antioxidant enzymes and radical scavengers. Compared with RIT alone, the use of RIT with ASMase inhibitor (imipramine) or with a lipid raft disruptor (e.g., methyl-beta-cyclodextrin or filipin) led to an increase in clonogenic cell survival in vitro and to larger tumors and less tissue DNA damage in vivo. These results were supported by an inhibitory effect of pravastatin on Auger RIT.

Conclusions: Cell membrane-mediated nontargeted effects play a significant role during Auger and alpha RIT, and drugs that modulate cholesterol level, such as statins, could interfere with RIT efficacy.
\end{abstract}

\section{Introduction}

During the last decade, several new radiopharmaceuticals were approved for targeted radionuclide therapy (TRT) of solid tumors or evaluated in clinical trials (1-6). These radiopharmaceuticals

IIRCM, Institut de Recherche en Cancérologie de Montpellier, INSERM U1194, Université de Montpellier, Institut Régional du Cancer de Montpellier, Montpellier, France. ${ }^{2}$ Institut Régional du Cancer de Montpellier, Université de Montpellier, Montpellier, France. ${ }^{3}$ UMR 1037 INSERM/UPS, Centre de Recherche en Cancérologie de Toulouse, Toulouse, France. ${ }^{4}$ Directorate for Nuclear Safety and Security, European Commission - Joint Research Centre, Karlsruhe, Germany. ${ }^{5}$ ORANO Med, Plano, Texas.

Corresponding Author: Jean-Pierre Pouget, Institut de Recherche en Cancérologie de Montpellier, INSERM U1194, Université de Montpellier, Institut Régional du Cancer de Montpellier, Montpellier F-34298, France. Phone: 33467613708; Fax: 33467613787; E-mail:

jean-pierre.pouget@inserm.fr are obtained by coupling a radionuclide to a peptide or an $\mathrm{mAb}$ (for radioimmunotherapy, RIT). Once administered to patients, they specifically recognize tumor cells and produce targeted irradiation to eradicate them. Although conventional external beam radiotherapy (EBRT) is mostly dedicated to localized tumors, TRT can be used for treating diffuse, metastatic disease or tumors close to organs at risk (7). DNA has been for long considered as the main, if not the only, target of radiation; however, it is today admitted that other subcellular targets, including mitochondria and cell membrane, should be considered during radiotherapy $(8,9)$. The cell membrane contains proteins, alcohols, such as sterols, and lipids (e.g., sphingolipids, glycolipids, phospholipids) that are structured in a bilayer to provide variable fluidity. We know from EBRT studies that radiation-induced reactive oxygen species (ROS) react with polyunsaturated fatty acids (10), leading to the generation of breakdown molecules, such as malondialdehyde, acrolein, and 4-hydroxy-2nonenal, that can react with cellular biomolecules (e.g., DNA, RNA, and also amino acids) to generate adducts. Irradiation also induces rapid formation of ceramide through the activation of acidic sphingomyelinases (ASMases) and the subsequent sphingomyelin hydrolysis at the plasma membrane $(11,12)$. Ceramide could be considered as a mediator of radiation that has an effect on the plasma membrane via the generation of ceramide-enriched 


\section{Translational Relevance}

This study shows that alpha radioimmunotherapy activity is mediated by targeted and nontargeted effects. Nontargeted effects and, to a lesser extent, targeted effects are modulated by the formation of ceramide-enriched large platforms and the subsequent activation of p38- and JNK-mediated signaling pathways. Nontargeted effects contribute to the cytotoxic and genotoxic effects beyond the particle range and may also counterbalance the heterogeneity in vector distribution. As targeted effects but not the nontargeted effects are dose related, these results have consequences on the planning and prediction of the therapeutic efficacy and side effects of targeted radionuclide therapy (TRT) using alpha particles. Moreover, patients undergoing treatment to modify lipid metabolism could respond differently to TRT.

microdomains termed rafts, but also on intracellular signaling molecules $(8,13,14)$.

Moreover, besides its direct response to radiation (defined as a targeted effect), cell membrane can also be involved in secondary intercellular communications that will further alter the biological functions of neighboring cells (15-18). When observed in cells that were not directly irradiated, these effects are defined as nontargeted effects of radiotherapy. Nontargeted effects have been predominantly described after low dose $(<0.5 \mathrm{~Gy})$ of EBRT, when the probability of cells to be hit by particles (targeted effect) is low (19-27). They may contribute to tumor eradication; however, they could also affect treatment planning because they are not dose-related and lead to unexpected side effects. As most of the vectors used in TRT bind to cell surface receptors, the probability for the cell membrane to be hit is much higher than during EBRT. This is even more marked when radionuclides used in clinical trials emit high linear energy transfer (high-LET) particles, namely alpha particles or Auger electrons $(3,5,6,28)$. This radiation type produces dense ionization in tissues over a short range $(<100 \mu \mathrm{m})$, leading to unrepairable complex lesions in biological constituents and possibly generating deleterious signals toward neighboring cells. Therefore, in association with strong dose heterogeneity and protracted exposure, nontargeted effects involving the cell membrane might play a significant role in the final therapeutic outcome of TRT.

Here, we investigated in vitro and in vivo the role of the cell membrane and of drugs that modulate cholesterol metabolism in targeted and nontargeted effects of RIT using alpha particle emitters, namely ${ }^{212} \mathrm{~Pb} /{ }^{212} \mathrm{Bi}$ and ${ }^{213} \mathrm{Bi}$ (alpha RIT), and the Auger emitter ${ }^{125} \mathrm{I}$ (Auger RIT).

\section{Materials and Methods}

\section{Cell lines and antibodies}

The A-431 vulvar squamous carcinoma, SK-OV-3 ovarian carcinoma, AN3CA endometrial carcinoma, and HCT116 colon adenocarcinoma human cell lines were obtained from the American Type Culture Collection (ATCC). HER2-positive A-431 cells were transfected with constructs encoding carcinoembryonic antigen (CEA, expressed by colorectal carcinoma cancer) and luciferase (29) to obtain the A-431 $1_{\text {CEA }}$ cell line. AN3CA cells naturally express Müllerian-inhibiting substance receptor II
(MISRII), whereas SK-OV-3 cells were transfected with a construct to express MISRII (SK-OV-3 $3_{\text {MISRII }}$ cells). HCT116 cells naturally express CEA. Cell line identities were confirmed using Powerplex 21 Kit (Promega). Mycoplasma test was routinely performed using the MycoAlert Mycoplasma Detection Kit (Lonza).

Then, SK-OV-3 $3_{\text {MISRII }}$ and AN3CA cells were chosen because they mimic ovarian peritoneal carcinomatosis when grafted i.p. in mice. Similarly, HCT116 and $431_{\text {CEA }}$ cells were chosen because they mimic colorectal peritoneal carcinomatosis. Small-volume peritoneal carcinomatosis originating from ovarian or colorectal cancer are suitable candidates for TRT using radionuclides that emit short-range particles (Auger, alpha; refs. 2, 30).

Parental and A-431 $1_{\mathrm{CEA}}$ and SK-OV-3 $3_{\text {MISRII }}$ cells were grown in DMEM, and HCT116 cells in RPMI 1640 medium. Media were supplemented with $10 \%$ (v/v) FCS, 2 mmol/L L-glutamine, $0.1 \mathrm{U} / \mathrm{mL}$ penicillin and $100 \mu \mathrm{g} / \mathrm{mL}$ streptomycin, and $1 \%$ geneticin (only for A-431 $41_{\text {CEA }}$ and SK-OV-3 $3_{\text {MISRII }}$ cells). AN3CA cells were cultured in MEM medium with $10 \%$ FCS, $1 \%$ penicillin, $0.1 \%$ streptomycin, $1 \%$ sodium pyruvate, and $1 \%$ nonessential amino acids. Cells were kept at $37^{\circ} \mathrm{C}$ in a humidified atmosphere containing $5 \% \mathrm{CO}_{2}$. The murine IgG1k mAb 35A7 against the CEA Gold 2 epitope and the anti-HER2 mAb trastuzumab (Herceptin, Genentech) were used to target CEA- and HER2expressing cells, respectively. The murine IgG1 anti-MISRII mAb $16 \mathrm{~F} 12$ produced by our team was used to target MISRII (31). The nonspecific PX IgG1 mAb from the mouse myeloma MOPC 21 (32) was used for control in vivo experiments.

The anti-CEA, anti-MISRII, and PX mAbs were purified from mouse hybridoma ascitic fluids by ammonium sulfate precipitation followed by ion exchange chromatography on DE52 cellulose (Whatman).

\section{Antibody conjugation and radiolabeling with ${ }^{212} \mathrm{~Pb},{ }^{213} \mathrm{Bi}$, or ${ }^{125} \mathrm{I}$}

The anti-HER2, 35A7 and PX mAbs were conjugated with TCMC (Macrocyclics) prior to radiolabeling at the specific activity of $37 \mathrm{MBq} / \mathrm{mg}$ with ${ }^{212} \mathrm{~Pb}$ (Orano Med), as described in ref. 33 (Supplementary Fig. S1). The anti-MISRII mAb was conjugated with 2-(P-SCN-benzyl)-cyclohexyl acid A-diethylenetriaminepentaacetic (CHX-A"- DTPA) and radiolabeled with ${ }^{213} \mathrm{Bi}$ (JRC) at the specific activity of $37 \mathrm{MBq} / \mathrm{mg}$, as described in ref. 31 . The anti-CEA mAb was radiolabeled also with ${ }^{125} \mathrm{I}$ (Perkin Elmer) at the specific activity of $370 \mathrm{MBq} / \mathrm{mg}$, as described in ref. 34 .

\section{In vivo $\mathrm{RIT}$ using ${ }^{212} \mathrm{~Pb}-,{ }^{125} \mathrm{I}-$, and ${ }^{213} \mathrm{Bi}$-labeled antibodies}

Female athymic nude Foxn $1^{\text {nu }}$ mice (6-8 weeks old; Envigo RMS Laboratories) were acclimated for 1 week. They were housed at $22^{\circ} \mathrm{C}$ and $55 \%$ humidity with a light-dark cycle of 12 hours, and food and water ad libitum. Body weight was determined weekly, and mice were clinically examined throughout the study. All animal experiments were performed in compliance with the French government guidelines and the INSERM standards for experimental animal studies (agreement B34-172-27). They were approved by the ethics committees of the Institut de Recherche en Cancérologie de Montpellier (IRCM/INSERM) and the Languedoc Roussillon region (CEEA LR France No. 36) for animal experiments (reference number: 1056).

To establish intraperitoneal tumor xenografts, $1 \times 10^{6}$ A- $431_{\text {CEA }}$ or $4.5 \times 10^{6}$ AN3CA cells in $0.3 \mathrm{~mL}$ DMEM or $0.3 \mathrm{~mL}$ DMEM/Matrigel (1:1), respectively, were i.p. grafted in mice. Six days after A-431 $\mathrm{CEA}$ graft, mice received (i) one-single i.p. 
injection of $1.48 \mathrm{MBq}{ }^{212} \mathrm{~Pb}$-anti-CEA, ${ }^{212} \mathrm{~Pb}$-anti-HER2, or ${ }^{212} \mathrm{~Pb}-\mathrm{PX} \mathrm{mAbs}(n=10,7$, and 6 mice; alpha RIT). The survival of these mice was previously reported (33); or (ii) ${ }^{125}$ I-anti-CEA mAb (Auger RIT: two i.p. injections of $37 \mathrm{MBq}$ at days 8 and 11); or methyl- $\beta$-cyclodextrin (MBCD, lipid raft disruptor; $300 \mathrm{mg} / \mathrm{kg}$; daily, from days 6 to 15 ); or both ${ }^{125}$ I-anti-CEA mAb and MBCD ( $n=10$ mice). Tumor growth was followed by bioluminescence (Xenogen, Perkin Elmer) measurement.

Mice xenografted with AN3CA cells (7 mice/group) were treated with (i) $\mathrm{NaCl}$; or (ii) daily i.p. injections of $300 \mathrm{mg} / \mathrm{kg} \mathrm{MBCD}$ from days 7 to 13 after graft; or (iii) one injection of ${ }^{213} \mathrm{Bi}$-antiMISRII mAb (37 MBq) at day 11 ; or (iv) both ${ }^{213} \mathrm{Bi}$-anti-MISRII $\mathrm{mAb}$ and MBCD. At day 30 after graft, mice were sacrificed, tumors collected, and the tumor mass was determined.

To investigate the role of pravastatin in Auger RIT, mice ( 8 mice/ group) were s.c. xenografted with $1 \times 10^{6} \mathrm{~A}-431_{\text {CEA }}$ cells in Matrigel and treated with (i) $\mathrm{NaCl}$; or (ii) daily i.p. injections of $40 \mathrm{mg} / \mathrm{kg}$ pravastatin from day 10 before graft until day 18 after graft; or iii) one injection of ${ }^{125} \mathrm{I}$-anti-CEA mAb (37 MBq) at day 8 and one at day 11 ; or (iv) both ${ }^{125} \mathrm{I}$-anti-CEA mAb and pravastatin. Tumor growth was followed by caliper measurement.

Ex vivo autoradiography and DNA damage assessment after RIT At various times $(4,17$, and 22 hours) following alpha $\left({ }^{212} \mathrm{~Pb} /{ }^{212} \mathrm{Bi}\right)$ or 24 hours after Auger RIT, mice bearing i.p. A-431 $1_{\text {CEA }}$ tumor cell xenografts were anesthetized, bled, and dissected. Tumors were collected and frozen after inclusion in OCT embedding matrix. Two consecutive $10-\mu \mathrm{m}$-thick frozen sections were analyzed by digital autoradiography (DAR) or by immunodetection of 53BP1, as described in ref. 34.

\section{In vitro determination of targeted and nontargeted cytotoxic effects of alpha RIT}

SK-OV-3 $3_{\text {MISRII }}$ (100 to 1,500 cells/well) and A-431 $1_{\text {CEA }}$ (100 to 5,000 cells/well) cells were plated in 6-well plates with $2 \mathrm{~mL}$ of medium. The following day, cells were incubated with ${ }^{213} \mathrm{Bi}$-anti-MISRII mAb (SK-OV-3 $3_{\text {MISRII }}$ cells) or ${ }^{212} \mathrm{~Pb}$-antiCEA $\mathrm{mAb}$ and ${ }^{212} \mathrm{~Pb}$-anti-HER2 $\mathrm{mAb}$ (A-431 $1_{\mathrm{CEA}}$ cells; 0-0.5 $\mathrm{MBq} / \mathrm{mL}$ ), or the corresponding unlabeled mAbs $(0-27 \mu \mathrm{g} / \mathrm{mL})$ for 90 minutes (donor cells). Culture medium was then removed, and cells were washed twice with $4 \mathrm{~mL}$ PBS. For investigating the nontargeted cytotoxic response, fresh medium $(2 \mathrm{~mL})$ was added to donor cells for 2 hours and then transferred to recipient cells that had been plated the day before (100 to 300 cells/well in 6-well plates).

For standard clonogenic assays, donor and recipient cells were then grown for 12 days, and colonies stained with crystal violet [2.5 g/L in 45:5 30\% (v/v) methanol/paraformaldehyde (PFA)]. Colonies containing 50 or more cells were scored, and the surviving fraction was calculated.

\section{In vitro measurement of DNA damage}

A-431 $1_{\text {CEA }}$ and SK-OV-3 $3_{\text {MISRII }}$ donor cells were seeded on coverslips in 6-well plates. The following day, they were incubated with $0.5 \mathrm{MBq} / \mathrm{mL}$ of ${ }^{212} \mathrm{~Pb}-\mathrm{mAbs}$ (A-431 $1_{\text {CEA }}$ cells) or $0.5 \mathrm{MBq} / \mathrm{mL}$ of ${ }^{213} \mathrm{Bi}$-mAbs (SK-OV-3 $3_{\text {MISRII }}$ cells) for 90 minutes. After radiolabeled antibody removal, fresh medium $(2 \mathrm{~mL})$ was added to donor cells for 2 hours and then transferred to recipient cells. Both donor and recipient cells were fixed with PFA and permeabilized, as described in ref. 34 (and Supplementary Methodology) for $\gamma$-H2AX/53BP1 foci detection.
The formation of micronuclei was determined in A- $431_{\text {CEA }}$ donor cells exposed to $0.5 \mathrm{MBq} / \mathrm{mL}^{212} \mathrm{~Pb}-\mathrm{mAbs}$ for 90 minutes and in recipient cells, as described in ref. 35 .

\section{ASMase and ceramide measurement, detection of lipid rafts}

Cells were incubated with ${ }^{213} \mathrm{Bi}$-anti-MISRII $\mathrm{mAb}(0.5 \mathrm{MBq} / \mathrm{mL})$ for 90 minutes or $\mathrm{H}_{2} \mathrm{O}_{2}(25 \mathrm{mmol} / \mathrm{L})$ at $37^{\circ} \mathrm{C}$ for 30 minutes. After three PBS washes, they were fixed in $3.7 \%(\mathrm{v} / \mathrm{v})$ PFA for 15 minutes and then washed 3 times in PBS. Cells were then incubated with a polyclonal rabbit anti-ASMase antibody (2 $\mu \mathrm{g} / \mathrm{mL}$; Santa Cruz Biotechnology, Inc.) and the anticeramide $15 \mathrm{~B} 4 \mathrm{mAb}\left(1: 50\right.$; Alexis Biochemicals) at $37^{\circ} \mathrm{C}$ for 1 hour. After three washes in PBS/2\% FCS, cells were incubated with Alexa Fluor 555-conjugated anti-rabbit (1:500; Invitrogen) or with Alexa Fluor 488-conjugated anti-mouse IgM (1:200; Invitrogen) in the dark for 1 hour. After three washes and resuspension in PBS, cells were analyzed by flow cytometry (Muse, Merck Millipore), and the G mean value (arbitrary units) was determined. To confirm ASMase role in RIT cytotoxicity, SK-OV-3 $3_{\text {MISRII }}$ cells were preincubated with $50 \mu \mathrm{mol} / \mathrm{L}$ imipramine (ASMase inhibitor) for 30 minutes following addition of ${ }^{213} \mathrm{Bi}$-anti-MISRII $\mathrm{mAb}(0.5 \mathrm{MBq} / \mathrm{mL})$ at $37^{\circ} \mathrm{C}$ for 90 minutes.

To visualize lipid rafts, SK-OV-3 $3_{\text {MISRII }}$ cells were plated on $12-\mathrm{mm}$ glass coverslips in culture dishes. After treatment, they were fixed in $3.7 \%$ (v/v) PFA and incubated with Alexa-488conjugated cholera toxin B (Molecular Probe) at $37^{\circ} \mathrm{C}$ for 45 minutes. After three washes in PBS, cells were fixed again in PFA for 10 minutes, and coverslips were then mounted in Mowiol and analyzed using a $63 \times$ NA objective and a Leica (Leica Microsystems) inverted microscope.

\section{In vitro role of lipid rafts in alpha RIT cytotoxic effects}

The role of lipid raft integrity in ${ }^{213} \mathrm{Bi}$-mAb-induced nontargeted cytotoxic effects was investigated by preincubating SK-OV-3 $3_{\text {MISRII }}$ cells with $4 \mathrm{mmol} / \mathrm{L} \mathrm{MBCD} \mathrm{(Sigma-Aldrich)} \mathrm{or}$ $2.5 \mu \mathrm{g} / \mathrm{mL}$ filipin (Sigma-Aldrich) for 30 minutes before adding ${ }^{213} \mathrm{Bi}$-anti-MISRII mAb for another 90 minutes in the presence of these lipid raft inhibitors. MBCD effect on cholesterol concentration in SK-OV-3 ${ }_{\text {MISRII }}$ cells incubated with MBCD was determined using a Cholesterol Quantification Kit (Sigma-Aldrich).

\section{Proteome kinase analysis and Western blotting}

A Human Phospho-Kinase Array (Proteome Profiler Array, $\mathrm{R} \& \mathrm{D}$ Systems) was used to detect the relative phosphorylation levels of 46 kinases in cell extracts of SK-OV- $3_{\text {MISRII }}$ donor (incubated with $0.5 \mathrm{MBq} / \mathrm{mL}^{213} \mathrm{Bi}$-anti-MISRII $\mathrm{mAb}$, or with $0.5 \mathrm{MBq} / \mathrm{mL}^{213} \mathrm{Bi}$-anti-MISRII $\mathrm{mAb}$ and $4 \mathrm{mmol} / \mathrm{L} \mathrm{MBCD}$ or $2.5 \mu \mathrm{g} / \mathrm{mL}$ filipin) and recipient cells, according to the manufacturer's protocol.

For Western blotting, HCT116, AN3CA, and SK-OV-3 $3_{\text {MISRII }}$ cell membrane, cytosolic protein fractions, and total lysates ( $40 \mu \mathrm{g}$ of each) were separated by SDS-PAGE and electrotransferred to polyvinylidene difluoride membranes (Amersham Pharmacia Biotech). After incubation with anti-phosphorylated (p) ERK, -p-SAP/JNK, -p-p38, and -p-NF- $\mathrm{KB}$ (p65) primary antibodies (Cell Signaling Technology), immune reactions were detected with horseradish peroxidase-conjugated goat anti-mouse or antirabbit (Sigma-Aldrich) secondary antibodies and the ECL detection system (Amersham Biosciences). 
In vitro analysis of $\mathrm{p} 38$ and JNK role

SK-OV-3 ${ }_{\text {MISRII }}$ donor cells were preincubated with $10 \mu \mathrm{mol} / \mathrm{L}$ SP600125 (JNK inhibitor) or $10 \mu \mathrm{mol} / \mathrm{L}$ SB203580 (p38 inhibitor) for 30 minutes before addition of 0 to $0.5 \mathrm{MBq} / \mathrm{mL}$ ${ }^{213} \mathrm{Bi}$-anti-MISRII $\mathrm{mAb}$ in the presence of the inhibitors for another 90 minutes. Then, medium was removed and the standard medium transfer protocol to donor cells described before was used.

\section{Analysis of oxidative stress}

SK-OV-3 $3_{\text {MISRII }}$ donor cells were preincubated with $20 \mu \mathrm{g} / \mathrm{mL}$ catalase (Sigma-Aldrich) or 0.5\% DMSO (Sigma-Aldrich) for 20 minutes before RIT with ${ }^{213} \mathrm{Bi}$-anti-MISRII mAb in the presence of catalase or DMSO for 90 minutes. Next, cells were washed twice with PBS, and new medium was added, and cells cultured until the appearance of colonies.

\section{Apoptosis induction and proliferation}

Apoptosis was measured in SK-OV-3 $3_{\text {MISRII }}$ donor cells preincubated with SP600125 (JNK inhibitor), SPB203580 (p38 inhibitor), imipramine (ASMase inhibitor), or MBCD (lipid raft disruptor) for 30 minutes before addition of 0 to $0.5 \mathrm{MBq} / \mathrm{mL}$ ${ }^{213} \mathrm{Bi}$-anti-MISRII mAb for 90 minutes. Then, radioactivity was removed, cells were washed with PBS, and apoptosis was measured at 48 hours after treatment using the TUNEL Detection Kit (Promega) according to the manufacturer's instructions.

Cell proliferation was measured in SK-OV-3 ${ }_{\text {MISRII }}$ cells using the EdU Cell Proliferation Assay (Merck Millipore). Briefly, EdU was added to the culture medium at a final concentration of $10 \mu \mathrm{mol} / \mathrm{L}$ immediately after RIT and left for 24 hours. Then, cells were fixed with $3.7 \%$ PFA and permeabilized with $0.1 \%$ Triton X-100. Fluorescent EdU was detected according to the manufacturer's instructions, and cells were analyzed using a $63 \times$ NA objective and a Leica (Leica Microsystems) inverted microscope.

\section{Statistical analysis}

All in vitro data were obtained from four independent experiments in triplicate. Data were analyzed using the Stata software v.13 (StataCorp) and described using mean, SD, median, and range. Comparisons between radiolabeled antibodies and control were performed using the nonparametric Kruskal-Wallis test (significance level set at 0.05). Pairwise comparisons were performed using the nonparametric Mann-Whitney test (considering a significance threshold at 0.013 to account for multiple testing). For in vivo experiments, radioactivity (cpm)-related DNA damage (number of foci) was modeled by linear regression.

\section{Results}

Nontargeted effects could contribute to the ${ }^{212} \mathrm{~Pb}$-anti-CEA mAb efficacy

The Kaplan-Meier analysis in our previous study (33) showed a significantly higher survival rate $(P<0.05)$ in mice bearing intraperitoneal A-431 $1_{\text {CEA }}$ tumors and treated with ${ }^{212} \mathrm{~Pb}$-antiHER2 mAb compared with ${ }^{212} \mathrm{~Pb}$-anti-CEA mAb (Fig. 1A). The absence of antitumor effect of the nonspecific ${ }^{212} \mathrm{~Pb}-\mathrm{PX} \mathrm{mAb}$ $(P=0.85 \mathrm{vs}$. $\mathrm{NaCl})$ demonstrated the absence of in vivo cytotoxic effects when ${ }^{212} \mathrm{~Pb}$ is not targeted to tumor cells. The higher therapeutic efficacy of the ${ }^{212} \mathrm{~Pb}$-anti-HER2 mAb could not be explained by a higher mean tumor uptake, because the mean doses were $28.1 \pm 2.1 \mathrm{~Gy}$ and $36.1 \pm 2.7 \mathrm{~Gy}$ for the ${ }^{212} \mathrm{~Pb}$ -
anti-HER2 and ${ }^{212} \mathrm{~Pb}$-anti-CEA mAb, respectively (Supplementary Methodology). Conversely, DAR analysis (Fig. 1B) showed that compared with tumors treated with ${ }^{212} \mathrm{~Pb}$-anti-HER2 $\mathrm{mAb}$, some tumor regions incorporated very low or no ${ }^{212} \mathrm{~Pb}$-anti-CEA mAb. Voxel dosimetry (Supplementary Methodology) indicated that about $30 \%$ of the tumor volume from ${ }^{212} \mathrm{~Pb}$-anti-CEA mAbtreated mice received $0 \mathrm{~Gy}$ (Fig. 1C). Conversely, in the ${ }^{212} \mathrm{~Pb}$-antiHER2 mAb group, all regions received some radioactivity, although the maximal voxel dose was about 2 times lower $(77$ for ${ }^{212} \mathrm{~Pb}$-anti-HER2 mAb vs. $140 \mathrm{~Gy}$ for ${ }^{212} \mathrm{~Pb}$-anti-CEA mAb).

Based on these observations, we hypothesized that in the absence of nontargeted effects, tumor cells that received $0 \mathrm{~Gy}$ in the ${ }^{212} \mathrm{~Pb}$-anti-CEA mAb-treated group should grow as fast as those in the $\mathrm{NaCl}$ group. Then, we established a theoretical growth curve using exponential tumor growth parameters of the $\mathrm{NaCl}$ treated group and considering an initial tumor volume corresponding to $30 \%$ of the volume of $\mathrm{NaCl}$-treated tumors measured at day 5 (Fig. 1D). According to this theoretical curve, the $30 \%$ of tumor volume that received $0 \mathrm{~Gy}$ in the ${ }^{212} \mathrm{~Pb}$-anti-CEA mAbtreated group should have grown much faster than what experimentally observed (Fig. 1D). The slower experimental growth rate of ${ }^{212} \mathrm{~Pb}$-anti-CEA mAb-treated tumors could be explained by the presence of molecular signals (i.e., nontargeted cytotoxic effects) between irradiated and nonirradiated tumor regions.

\section{${ }^{212} \mathrm{~Pb}$-anti-CEA mAbs produce similar DNA damage levels in} irradiated and nonirradiated tumor regions

To test the in vivo occurrence of nontargeted effects associated with the ${ }^{212} \mathrm{~Pb}$-anti-CEA mAb treatment, we asked whether genotoxic effects were present also in nonirradiated tumor regions. To this aim, we investigated in tumor sections from mice treated with ${ }^{212} \mathrm{~Pb}$-mAbs the relationship between the number of 53BP1 foci, a protein that rapidly relocalizes to nuclear foci upon DNA damage, and radioactivity level in the tumors collected at 17 hours postRIT, when the mean dose rate was still about $50 \%$ of the initial dose rate (1.1 vs. $2.1 \mathrm{~Gy} \cdot \mathrm{h}^{-1}$ at 4 hours post-RIT, data not shown; Fig. 1E). The number of 53BP1 foci per $\mathrm{mm}^{2}$ tumor was relatively constant in ${ }^{212} \mathrm{~Pb}$-anti-CEA mAb-treated tumors, independently of the radioactivity level calculated by DAR (between $5.9 \pm 0.2$ and $7.6 \pm 0.3 \mathrm{foci} / \mathrm{cpm} / \mathrm{mm}^{2}$ ), and the slope of the corresponding regression curve was not different from zero $(P=0.072)$. Conversely, 53BP1 foci were proportional to the radioactivity level in ${ }^{212} \mathrm{~Pb}$-anti-HER $2 \mathrm{mAb}$ and ${ }^{212} \mathrm{~Pb}$-PX-treated tumors (Fig. 1F), and the slope was significantly different from zero $(P=0.012$ and $P=0.023$, respectively). The number of 53BP1 foci per cell ranged from $4.0 \pm 0.3$ to $8.6 \pm 0.4$ for ${ }^{212} \mathrm{~Pb}$-anti-HER2 $\mathrm{mAb}$, from $1.9 \pm 0.1$ to $3.5 \pm 0.2$ for ${ }^{212} \mathrm{~Pb}-\mathrm{PX}$ $\mathrm{mAb}$, and was above the background level of $0.8 \pm 0.1$ foci per cell in $\mathrm{NaCl}$-treated tumors.

\section{Nontargeted cytotoxic effects are observed after alpha RIT}

To confirm in vitro the contribution of targeted and nontargeted cytotoxic effects during alpha RIT, we determined the clonogenic cell survival of A-431 $1_{\mathrm{CEA}}$ and SK-OV-3 $3_{\mathrm{MISRI}}$ donor cells exposed to radiolabeled antibodies and of the corresponding recipient cells In donor A-431 $1_{\text {CEA }}$ cells, ${ }^{212} \mathrm{~Pb}$-mAbs strongly reduced clonogenic cell survival at test activities as low as $0.03 \mathrm{MBq} / \mathrm{mL}$ (Fig. 2A). Beyond $0.06 \mathrm{MBq} / \mathrm{mL}$, clonogenic cell survival was lower than $1 \%$. Although less pronounced than in donor cells (targeted effect), clonogenic cell survival was reduced also in recipient cells (nontargeted effects). Targeted and nontargeted cytotoxic effects 
A $\mathrm{A}-431_{\mathrm{CEA}}$ tumor xenografts
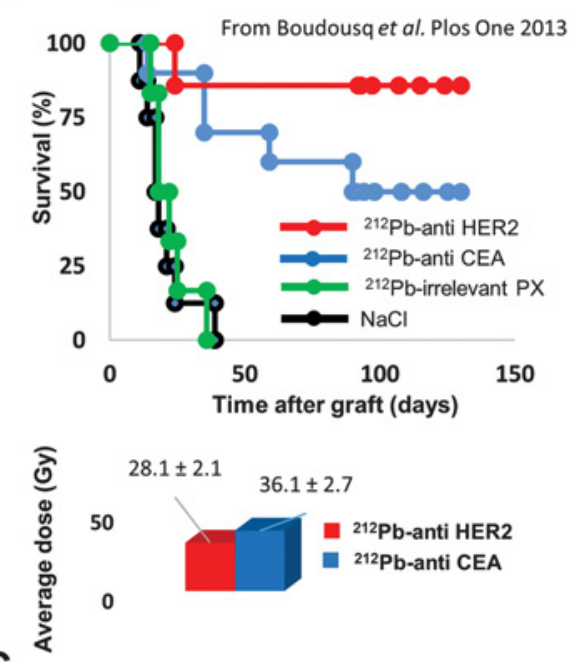

C

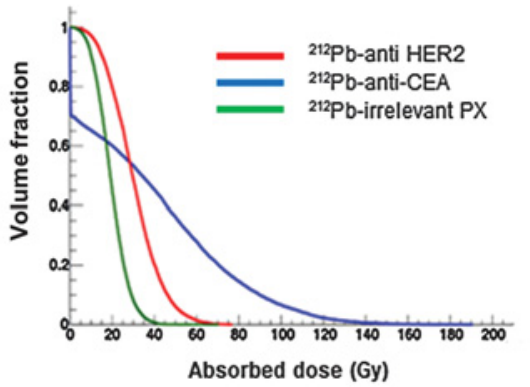

E
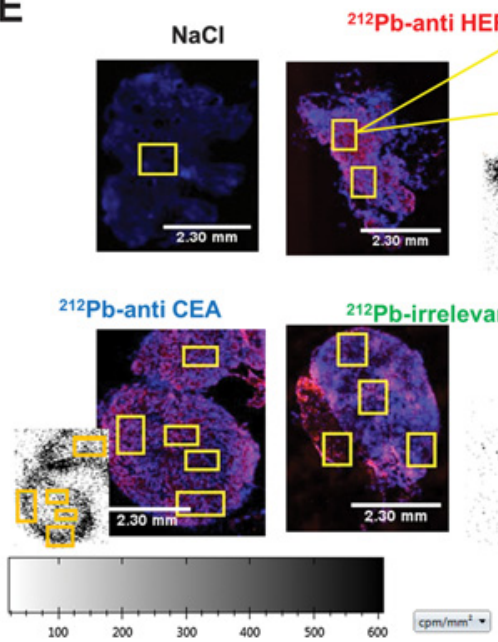

B

${ }^{212} \mathrm{~Pb}$-anti HER2 ${ }^{212} \mathrm{~Pb}$-anti CEA ${ }^{212} \mathrm{~Pb}$-irrelevant $\mathrm{PX}$
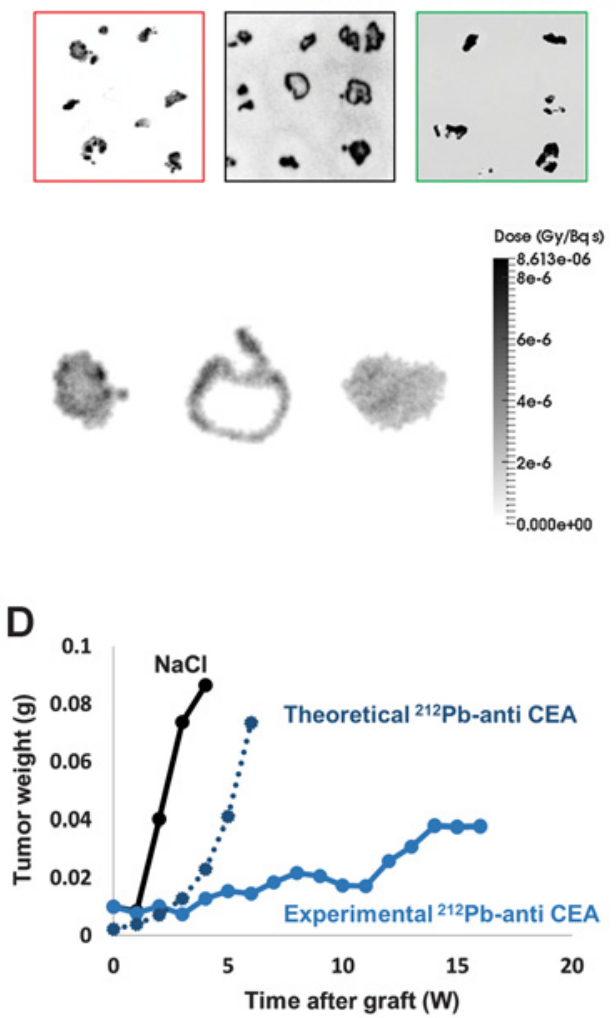

$\mathbf{F}$

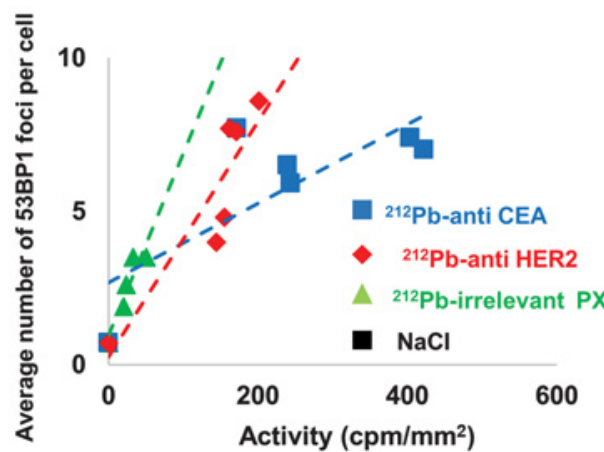

Figure. 1.

In vivo evidence for nontargeted effects. A, Kaplan-Meier survival analysis of mice bearing intraperitoneal A-431 tumor cell xenografts that received a single i.p. injection of $\mathrm{NaCl}$, or $1.48 \mathrm{MBq}$ of ${ }^{212} \mathrm{~Pb}$-anti-CEA mAb, ${ }^{212} \mathrm{~Pb}$-anti-HER2 $\mathrm{mAb}$, or ${ }^{212} \mathrm{~Pb}-\mathrm{PX}$ (nonspecific mAb) at day 5 after graft (data from ref. 33 ).

B, Representative DAR images of tumor sections at 17 hours after RIT. Gray scale bar shows the calculated dose per decay (Gy/Bq.S). C, Histograms showing the tumor volume in function of the absorbed dose for A-431 $1_{\text {CEA }}$ cell xenografts from mice treated with ${ }^{212} \mathrm{~Pb}$-anti-HER2 mAb (red), ${ }^{212} \mathrm{~Pb}-\mathrm{anti}-\mathrm{CEA}$ mAb (blue), and ${ }^{212} \mathrm{~Pb}-\mathrm{PX}$ (green). A representative tumor for each group was selected and used as input for the simulation of the voxel absorbed dose. About $30 \%$ of the ${ }^{212} \mathrm{~Pb}$-anti-CEA mAb-treated tumor received $\mathrm{O}$ Gy of absorbed dose. $\mathbf{D}$, The experimental tumor growth was determined by measuring the bioluminescence signal over time $\left({ }^{212} \mathrm{~Pb}\right.$-anti-CEA mAb-treated mice). The theoretical curve was established by considering that $30 \%$ of the tumor volume of ${ }^{212} \mathrm{~Pb}$-anti-CEA mAb-treated mice behaved like tumors from NaCl-treated mice (theoretical curve). E, IHC analysis of 53BP1 foci in the frozen section adjacent to the one used for DAR. DAR images (as reported in B) are also shown. The distribution of 53BP1 foci was determined in 100 cells for each tumor area (6-7 tumor areas for each mouse). Some of the selected tumor areas are highlighted in yellow in the IHC analysis panels and the relevant DAR panels. F, For each radiolabeled ${ }^{212} \mathrm{~Pb}-\mathrm{mAb}$, the average number of 53BP1 foci per cell (counted in each tumor area) was plotted as a function of the activity $\left(\mathrm{cpm} / \mathrm{mm}^{2}\right.$ ) determined by DAR in the corresponding tumor area. 
A $A-431_{\text {CEA }}$ cells

골

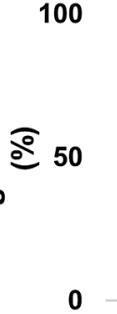

$0.00 \quad 0.03$
Donor cells

${ }^{212} \mathrm{~Pb}$-anti-HER2

$\square$ 212Pb-anti-CEA

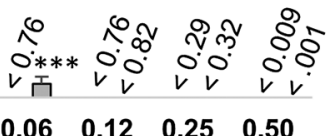

Recipient cells

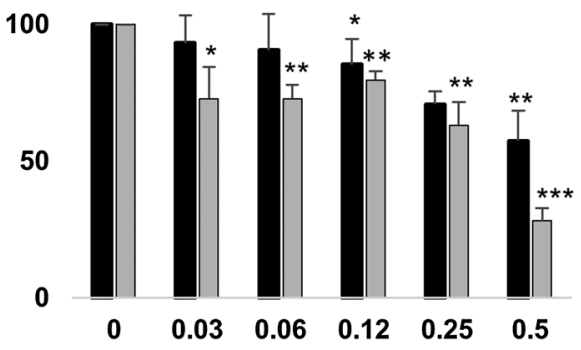

Test activity of donor cells (MBq/mL)

B SK-OV-3 MISRII $_{\text {cells }}$

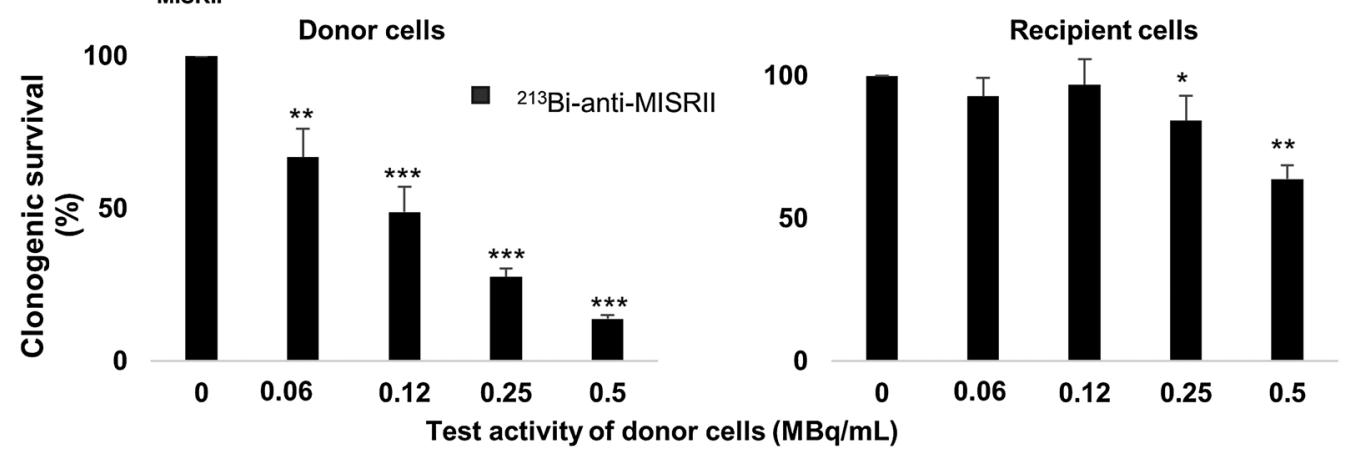

C SK-OV-3 MISRII $_{\text {cells }}$

Donor cells $\square$ Recipient cells
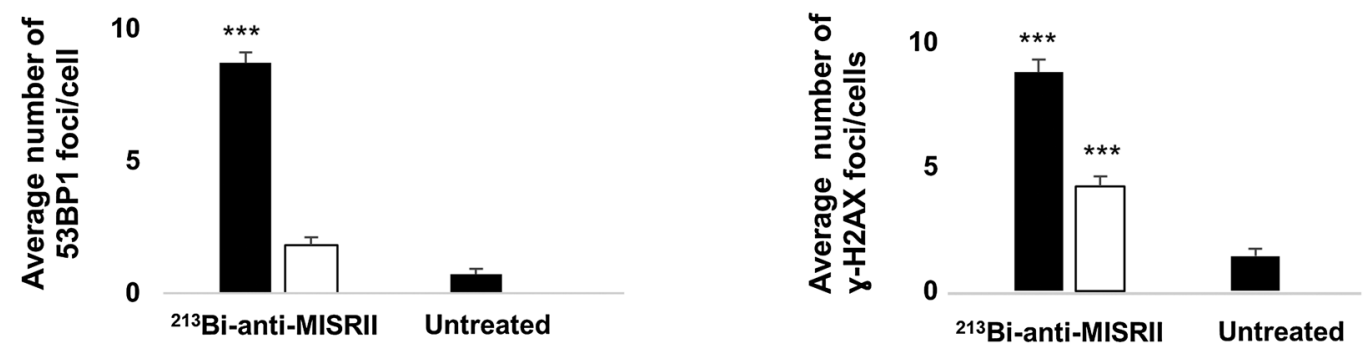

D SK-OV-3 MISRII $_{\text {cells }}$

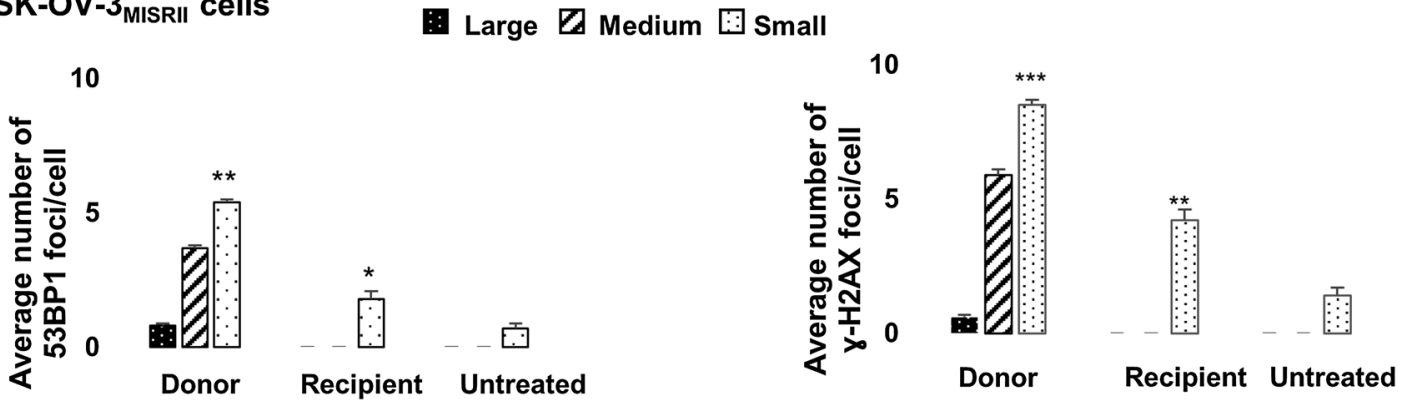

Figure 2.

In vitro evidence for nontargeted effects. Clonogenic cell survival was assessed in donor and recipient cells 12 days after exposure to increasing activities $(0-0.5 \mathrm{MBq} / \mathrm{mL}$ ) of radiolabeled mAbs for 90 minutes (donor cells), or incubation in culture medium in which donor cells were cultured for 2 hours (recipient cells). A, A-31 $1_{\text {CEA }}$ donor cells were exposed to ${ }^{212} \mathrm{~Pb}$-anti-CEA (gray) or ${ }^{212} \mathrm{~Pb}$-anti-HER2 mAbs (black). B, SK-OV-3 MISRII $_{\text {donor cells were exposed to }}{ }^{213} \mathrm{Bi}$-antiMISRII mAb. C, The mean number \pm SD of 53BP1 and $\gamma \mathrm{H} 2 \mathrm{AX}$ foci per cell was determined by immunofluorescence in SK-OV-3 $\mathrm{MISRII}$ donor cells exposed to $0.5 \mathrm{MBq} / \mathrm{mL}{ }^{213} \mathrm{Bi}$-anti-MISRII $\mathrm{mAb}$ and in the corresponding recipient cells ( $n=100$ cells/group). D, $53 \mathrm{BP} 1$ and $\gamma \mathrm{H} 2 \mathrm{AX}$ foci were classified as large, medium, and small in donor, recipient, and untreated cells according to size criteria shown in Supplementary Fig. S3. Results are the mean \pm SD of three experiments performed in triplicate. ${ }^{*}, P<0.05 ;{ }^{* *}, P<0.01$; and ${ }^{* * *}, P<0.001$ compared with untreated cells. 
were also observed in SKOV3 $3_{\text {MISRII }}$ donor cells exposed to the ${ }^{213} \mathrm{Bi}$-anti-MISRII $\mathrm{mAb}$ and in recipient cells (Fig. 2B). In both cell models, neither targeted nor nontargeted cytotoxic effects were detected after exposure to unlabeled antibodies (Supplementary Fig. S2).

DNA double-strand breaks induced by targeted and nontargeted effects of alpha RIT are associated with different types of 53BP1 and $\gamma$-H2AX foci

We then evaluated the expression of 53BP1 and $\gamma \mathrm{H} 2 \mathrm{AX}$, two DNA double-strand break (DSB) markers, in SK-OV-3 $3_{\text {MISRI }}$ donor cells exposed to ${ }^{213} \mathrm{Bi}$-anti-MISRII mAbs for 90 minutes and in recipient cells (Fig. 2C and D; Supplementary Fig. S3A). Quantification of the mean number of 53BP1 and $\gamma \mathrm{H} 2 \mathrm{AX}$ foci per cell showed that upon irradiation, DNA DSBs were produced in both donor and recipient cells compared with untreated control (Fig. 2C), confirming the occurrence of nontargeted genotoxic effects. Moreover, we could classify foci in three subgroups according to their size (arbitrarily defined as large, medium, and small) in donor cells, but we only detected small foci in recipient and control cells (Fig. 2D). Foci sizes are reported in Supplementary Fig. S3A. The mean number of large, medium, and small 53BP1 foci per donor cell was $0.8 \pm 0.1,3.7 \pm 0.2$, and $5.4 \pm 0.3$, respectively (Fig. 2D). Conversely, the mean number of 53BP1 small foci was $1.8 \pm$ 0.3 in recipient cells, and $0.7 \pm 0.1$ in untreated cells. We obtained similar results for $\gamma \mathrm{H} 2 \mathrm{AX}$ foci (Fig. 2D, right plot), and in A-431 $\mathrm{CEA}$ cells exposed to ${ }^{212} \mathrm{~Pb}-\mathrm{mAb}$ (Supplementary Fig. S3B; only for 53BP1 foci for technical reasons). We hypothesized that large foci were caused by the recruitment of a higher number of $\gamma$-H2AX and 53BP1 proteins compared with medium and small foci, and that consequently, they corresponded to more complex lesions. As a consequence of misrepaired DNA DSBs, the number of micronuclei was significantly increased in both donor and recipient A-431 $1_{\mathrm{CEA}}$ cells after exposure to ${ }^{212} \mathrm{~Pb}-\mathrm{mAbs}$ (Supplementary Fig. S3C).

\section{Lipid rafts participate in the targeted and nontargeted cytotoxic} effects

As radiolabeled mAbs bind to cell surface receptors, the cell membrane is the first target of irradiation. We investigated whether cell membrane modifications could be involved in alpha RIT-targeted and nontargeted effects. Using cholera toxin $\mathrm{B}$, we first showed the formation of lipid raft domains in SKOV- $3_{\text {MISRII }}$ cells exposed to ${ }^{213} \mathrm{Bi}$-mAbs (Fig. $3 \mathrm{~A}$ ). Ceramide, a class of cell membrane sphingolipids, can be formed by sphingomyelin hydrolysis catalyzed by ASMase. With cholesterol and proteins, ceramide can contribute to the formation of ceramide-enriched large domains that can be identified as lipid rafts. We found that compared with untreated cells, ASMase activation (Fig. 3B, top) and ceramide production (Fig. 3B, bottom) were increased in SK-OV-3 $3_{\text {MISRII }}$ cells exposed to ${ }^{213} \mathrm{Bi}$ $\mathrm{mAbs}$. To test the role of ASMase and of lipid rafts in alpha RIT cytotoxic effects, we incubated SK-OV-3 $3_{\text {MISRII }}$ cells with ${ }^{213} \mathrm{Bi}$ anti-MISRII mAb alone or with imipramine, an ASMase inhibitor (Fig. 3C), or with lipid raft disruptors (Fig. 3D): filipin that sequesters cholesterol, or MBCD that depletes cholesterol. Clonogenic cell survival of both donor and recipient cells was increased in the presence of imipramine or of lipid raft disruptors. We confirmed that the cholesterol level of cells treated with MBCD was lower than in untreated cells (Fig. 3E).
The MAP kinases $\mathrm{p} 38$ and JNK1/2 are activated during alpha RIT and contribute to cell death

As lipid raft are known to activate intracellular signaling pathways, we analyzed SK-OV-3 $3_{\text {MISRII }}$ donor (i.e., exposed to the ${ }^{213} \mathrm{Bi}$ anti-MISRII mAb) and recipient cells extracts using a phosphoprotein kinase array (Fig. 3F; Supplementary Fig. S4A). Compared with untreated cells or cells exposed to unlabeled anti-MISRII $\mathrm{mAb}$, several kinases were activated in cells exposed to ${ }^{213} \mathrm{Bi}$-antiMISRII mAb. p38- $\alpha$ kinase, c-JUN $N$ terminal kinases $1 / 2 / 3$ (JNK $1 / 2 / 3$ ), and the downstream c-JUN transcription factor were among the most significantly activated phosphorylation pathways. Some growth factors also were activated, such as ERK1/2, AKT1/2, CREB, GSK3, and MSK1/2. Yes, Fyn, and Fgr of the SrcA family of protein tyrosine kinases, LCK, WNK, STAT 3 and 6 , HSP60, and HSP27 also were activated (Fig. 3F).

We obtained similar results in recipient cells. Among the most notable differences was the activation of proline-rich AKT1 substrate 1 (PRAS40) and 5'-AMP-activated protein kinase (AMPK) subunit $\alpha 1$ (Supplementary Fig. S4A).

We confirmed the increased phosphorylation of p38, JNK1/2/3 in vitro by Western blotting using protein lysates of untreated and donor and recipient SK-OV-3 $3_{\text {MISRII }}$ and AN3CA cells (Fig. 4A; Supplementary Fig. S4B).

We showed using EdU that cell proliferation was reduced in SK-OV- $3_{\text {MISRI }}$ cells exposed to ${ }^{213} \mathrm{Bi} \mathrm{mAbs}$ and that apoptosis (using TUNEL assay) was induced (Fig. 4B and C; Supplementary Fig. S5A). Conversely, cell proliferation was restored at 48 hours and apoptosis reduced when pharmacologic inhibitors of p38 (SB203580) and of JNK1/2/3 (SP600125; and also MBCD or imipramine) were used (Fig. 4B and C).

Finally, compared with exposure to ${ }^{213} \mathrm{Bi}$-mAbs alone, clonogenic cell survival was increased in both donor and recipient cells when SK-OV-3 $3_{\text {MISRII }}$ donor cells were incubated with ${ }^{213} \mathrm{Bi}-\mathrm{mAbs}$ in the presence of SB203580 or SP600125. These results indicate that the $\mathrm{p} 38$ and JNK1/2/3 signaling pathways contribute to the targeted and nontargeted cytotoxicity of ${ }^{213} \mathrm{Bi}$-mAbs (Fig. 4D).

Lipid raft disruption is accompanied by loss of alpha RITinduced $\mathrm{p} 38$ and JNK1/2/3 phosphorylation

To investigate the role of lipid raft integrity on the RIT-induced expression of the previously identified signaling pathways, we performed a phosphoprotein kinase array analysis using donor and recipient cells exposed to ${ }^{213} \mathrm{Bi}$-anti-MISRII $\mathrm{mAb}$ in the presence of MBCD (Fig. 5A; Supplementary Fig. S5B), which decreased the mean cholesterol levels (Fig. 3E), or filipin (Supplementary Fig. S6). Phosphorylated p38 and JNK1/2/3 expression levels were strongly reduced in both donor and recipient cells exposed to ${ }^{213}$ Bi-anti-MISRII mAb + MBCD or filipin compared with cells incubated only with ${ }^{213} \mathrm{Bi}$-anti-MISRII mAb. Western blot analysis of tumors collected from mice treated with $37 \mathrm{MBq}$ ${ }^{213} \mathrm{Bi}$-anti-MISRII mAb confirmed the decreased phosphorylation of $\mathrm{p} 38$ and SAPK/JNK in the presence of MBCD treatment (Fig. 5B) in vivo.

\section{Oxidative stress is involved in the nontargeted response to} alpha RIT

As ROS can activate ASMase, we assessed the role of oxidative stress in the targeted and nontargeted effects of alpha RIT by incubating donor cells with catalase or DMSO (two radical scavengers) during exposure to ${ }^{213} \mathrm{Bi}$-anti-MISRII mAb (Fig. 5C). Compared with cells exposed to ${ }^{213} \mathrm{Bi}$-anti-MISRII mAb alone, 

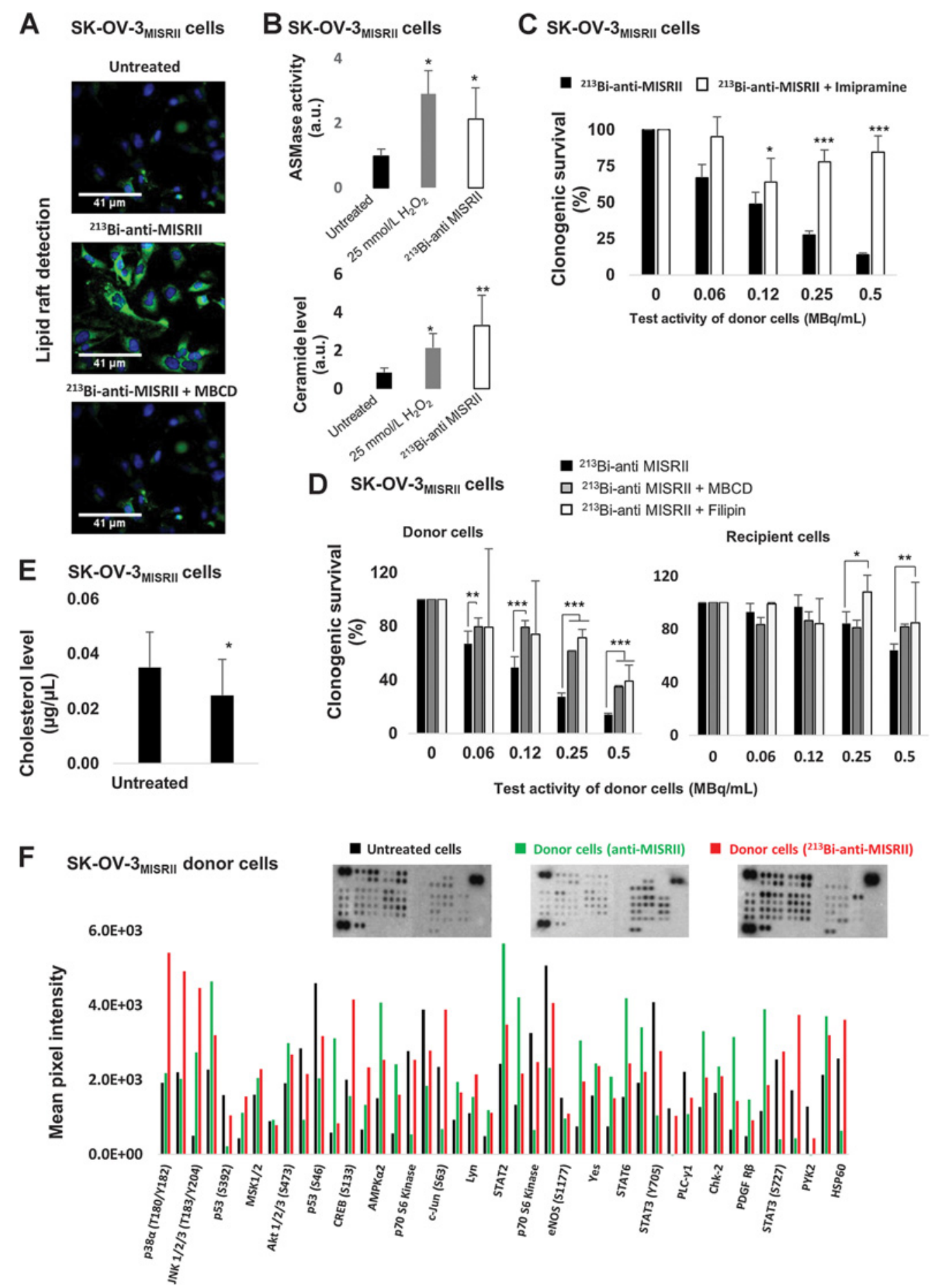

Figure 3.

Lipid raft-mediated activation of signaling pathways. A, Lipid rafts were detected by immunofluorescence analysis using Alexa-488-conjugated cholera toxin B (green) in untreated and treated ${ }^{213} \mathrm{Bi}-\mathrm{mAb}$ or $\left.{ }^{213} \mathrm{Bi}-\mathrm{mAb}+\mathrm{MBCD}\right) \mathrm{SK}-\mathrm{OV}-3_{\text {MISRII }}$ cells. Nuclei were stained with Hoechst (blue). B, ASMase and ceramide levels were measured in SK-OV-3 $3_{\text {MISRII }}$ cells by flow cytometry analysis after incubation with $25 \mathrm{mmol} / \mathrm{L} \mathrm{H}_{2} \mathrm{O}_{2}$ (positive control) or with ${ }^{213} \mathrm{Bi}$-anti-MISRII mAbs. C, Clonogenic survival of SK-OV-3 MISRII $_{\text {donor cells incubated with }}{ }^{213} \mathrm{Bi}-\mathrm{mAb}$ or ${ }^{213} \mathrm{Bi}-\mathrm{mAb}$ and imipramine (an ASMase inhibitor). D, Clonogenic cell survival of SK-OV-3 MISRII donor cells coincubated or not with ${ }^{213} \mathrm{Bi}$-anti-MISRII mAb and filipin or MBCD (two lipid raft disruptors) and of the corresponding recipient cells. E, Cholesterol level in cell extracts of untreated and MBCD-treated SK-OV-3 $3_{\text {MSRII }}$ cells. Results are the mean \pm SD of three (four for the clonogenic assays) experiments performed in triplicate. ${ }^{*}, P<0.05$; ${ }^{* *}, P<0.01$; and ${ }^{* * *}, P<0.001$ compared with untreated cells. F, The phosphorylation level of 46 kinases activated in SK-OV-3 $3_{\text {MISRII }}$ donor cells exposed or not (untreated) to unlabeled or ${ }^{213}$ Bi-labeled anti-MISRII mAbs was assessed using the Human Phospho-Kinase Array (Proteome Profiler Array; R\&D Systems). For each kinase, Image J software was used to determine the pixel intensity. 
A SK-OV-3 $3_{\text {MISRII }}$ cells
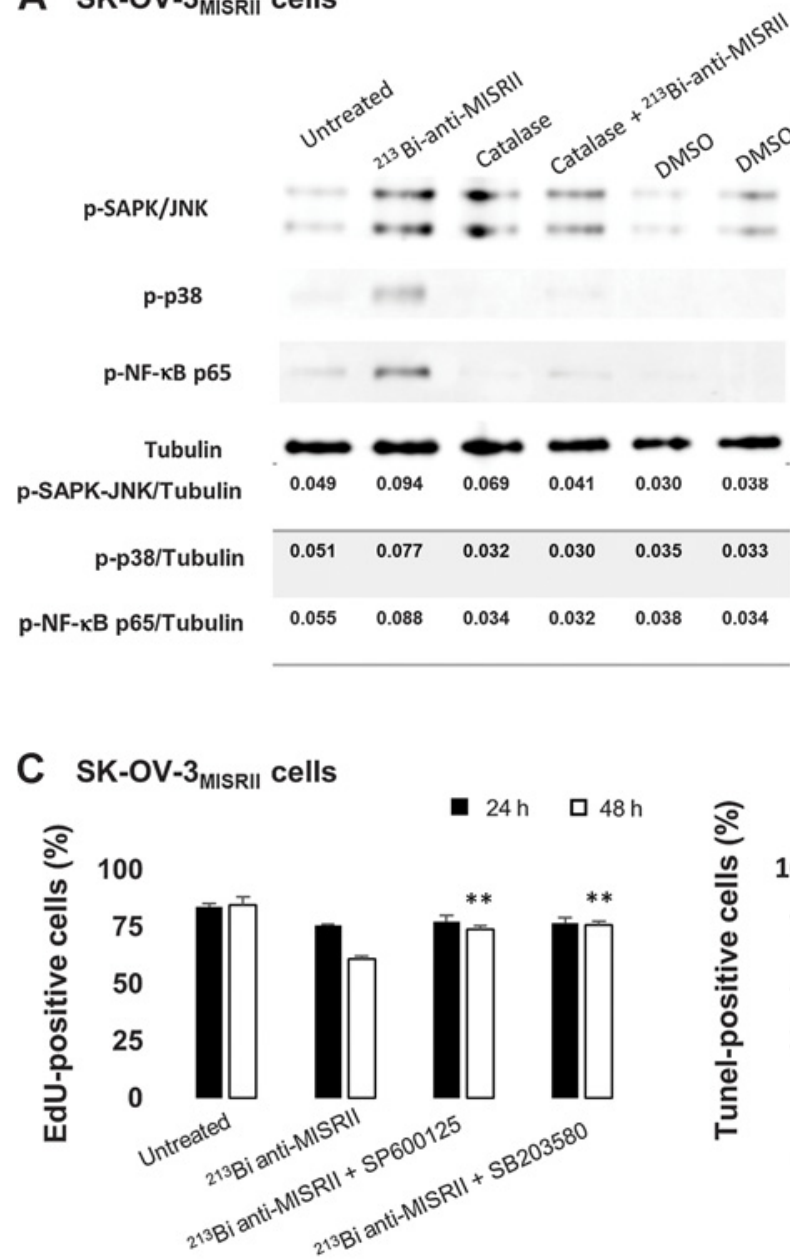

B SK-OV- $3_{\text {MISRII }}$ cells

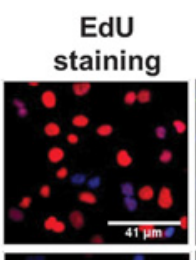

TUNEL staining
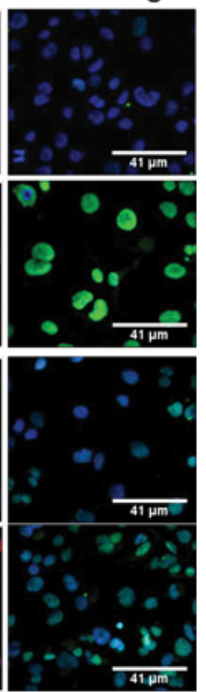

Untreated

${ }^{213} \mathrm{Bi}-$ anti MISRII

${ }^{213} \mathrm{Bi}$-anti MISRII

+ SP600125

${ }^{213} \mathrm{Bi}$-anti MISRII

+ SB203580

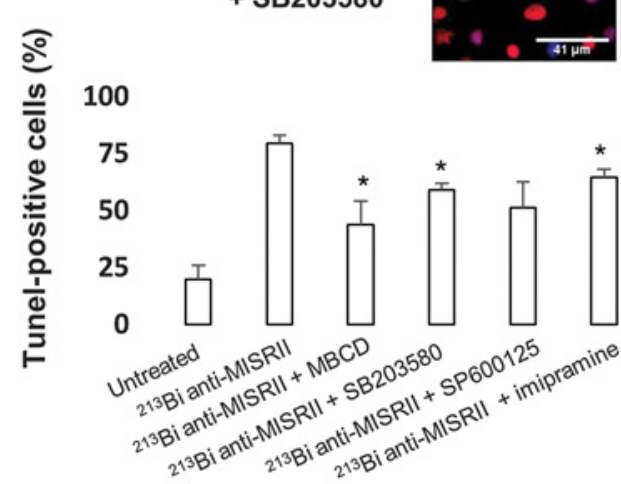

D SK-OV-3 MISRII $_{\text {cells }}$

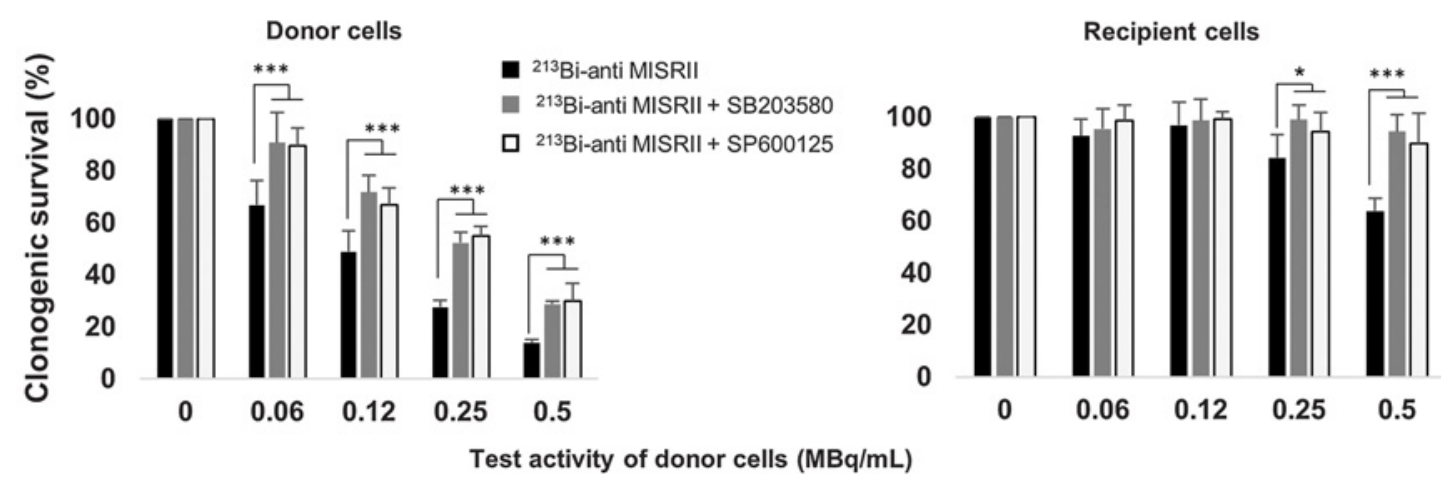

Figure 4.

Pharmacologic inhibition of MAPK pathways and involvement of lipid rafts in vitro. A, The expression of phosphorylated p38 ( $p$-p38), SAPK/JNK ( $p$-SAPK/JNK), and NF- $\mathrm{KB}(\mathrm{p}-\mathrm{NF}-\kappa \mathrm{B})$ was determined by Western blotting using extracts of SK-OV-3 ${ }_{\text {MISRII }}$ cells exposed to ${ }^{213} \mathrm{Bi}-\mathrm{mAbs}$ and/or catalase or DMSO. B, EdU and

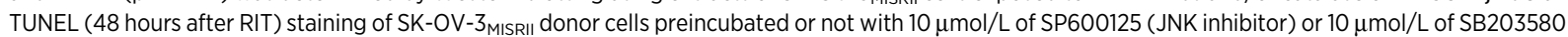
(p38 inhibitor) for 30 minutes and then exposed to $0-0.5 \mathrm{MBq} / \mathrm{mL}{ }^{213} \mathrm{Bi}$-anti-MISRII mAb in the presence or not of the inhibitors for 90 minutes. C, Quantification of EdU-positive (at 24 and 48 hours after treatment) and TUNEL-positive (at 48 hours) SK-OV-3 ${ }_{\text {MISRII }}$ cells relative to all cells. D, SK-OV-3 ${ }_{\text {MISRII }}$ donor cells were preincubated or not with $10 \mu \mathrm{mol} / \mathrm{L}$ of SP600125 or $10 \mu \mathrm{mol} / \mathrm{L}$ of SB203580 for 30 minutes and then exposed to $0-0.5 \mathrm{MBq} / \mathrm{mL}{ }^{213} \mathrm{Bi}$-anti-MISRII mAb in the presence or not of the JNK and p38 inhibitors. Clonogenic cell survival was determined in donor and recipient cells. Results are the mean \pm SD of four experiments performed in triplicate. ${ }^{*}, P<0.05$; ${ }^{* *}, P<0.01$; and ${ }^{* * *}, P<0.001$ compared with untreated cells. 

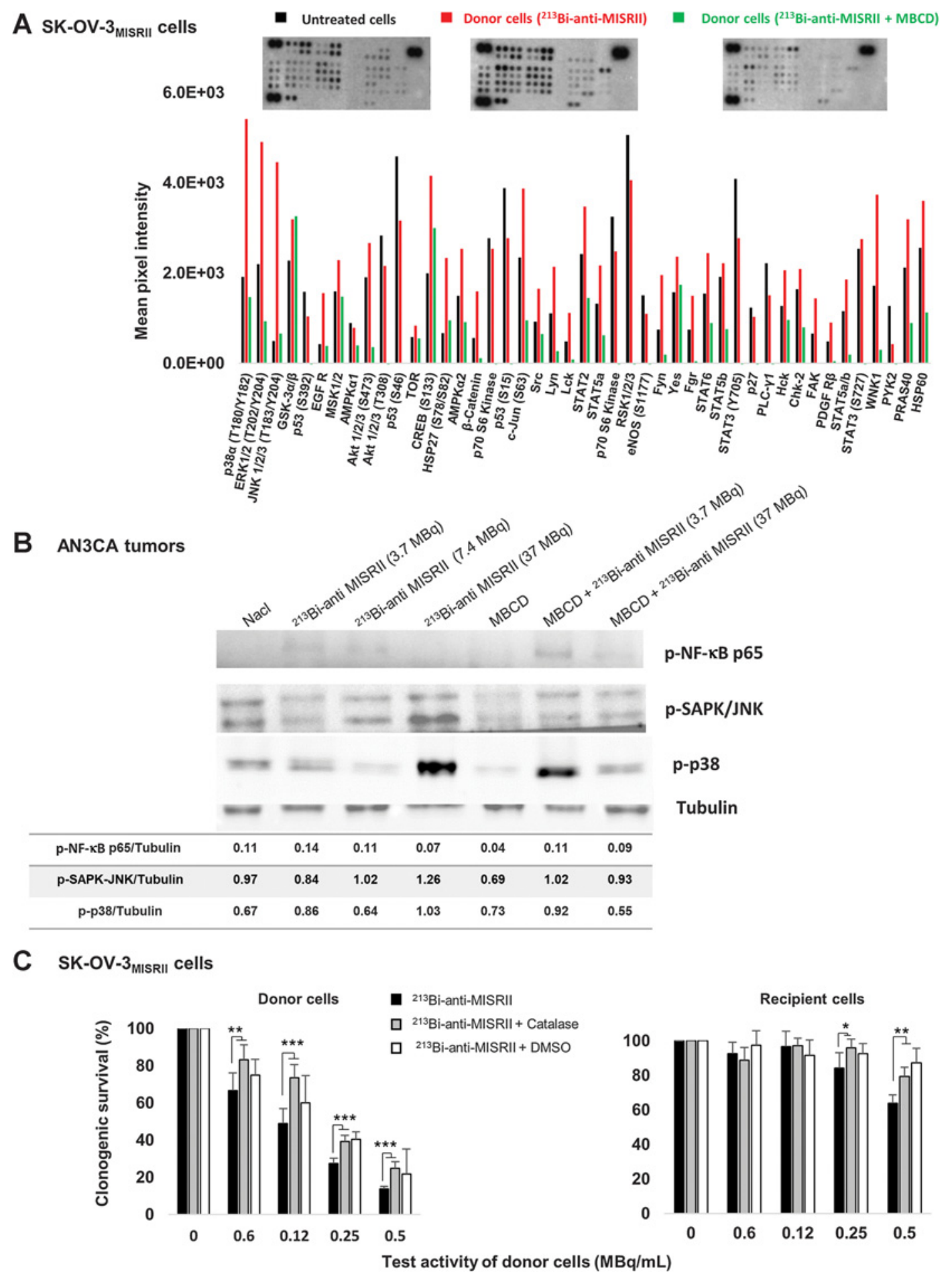

Figure 5.

MBCD effect on protein kinase expression and antioxidant defenses during alpha RIT in SK-OV-3MISPI cells. A, The phosphorylation level of 46 kinases activated

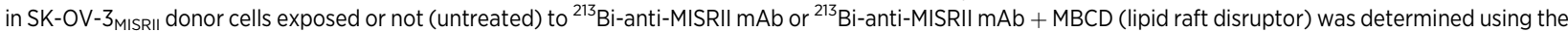
Human Phospho-Kinase Array (Proteome Profiler Array; R\&D Systems). For each kinase, ImageJ software was used to determine the pixel intensity. B, The expression of phosphorylated (p)-p38, p-SAPK/JNK, and p-NF-kB was determined by Western blotting using extracts of AN3CA tumors of mice exposed to low (3.7 MBq and 7.4 MBq) and high activities (37 MBq) of ${ }^{213} \mathrm{Bi}$-anti-MISRII mAb combined or not with MBCD. C, SK-OV-3 MISRII donor cells were preincubated with catalase or $0.5 \%$ DMSO for 20 minutes before exposure to ${ }^{213} \mathrm{Bi}$-anti-MISRII mAbs in the presence of these ROS scavengers. Control cells were incubated only with ${ }^{213} \mathrm{Bi}$-anti-MISRII mAbs. Clonogenic cell survival of donor (left) and recipient cells (middle) was measured. Results are the mean $\pm \mathrm{SD}$ of four experiments performed in triplicate. ${ }^{*}, P<0.05 ;{ }^{* *}, P<0.01$; and ${ }^{* * *}, P<0.001$ compared with cells exposed only to ${ }^{213} \mathrm{Bi}$-anti-MISRII mAb. 
coincubation with catalase led to a significant increase in clonogenic cell survival of donor $(P<0.001)$ and recipient cells $(P<0.05)$. For DMSO, survival was only statistically increased in donor cells exposed to $0.25 \mathrm{MBq} / \mathrm{mL}(P<0.001)$ and in recipient cells incubated with medium from donor cells exposed to 0.25 and $0.5 \mathrm{MBq} / \mathrm{mL}$ of ${ }^{213} \mathrm{Bi}$-anti-MISRII $\mathrm{mAb}(P<0.05$ and $P<0.01$, respectively). Catalase and DMSO also reduced the level of p-p38, p-SAPK/JNK, and p-NF- $\mathrm{KB}$ p65 (Fig. 4A). However, comparison of the catalase and DMSO effects in donor and recipient cells indicated that the relative contribution of ROS to the cytotoxic effect was much lower in donor than in recipient cells (Fig. 5C).

Then, we used an oxidative stress membrane array to analyze the expression of proteins involved in redox mechanisms (Supplementary Methodology). In SK-OV-3 $3_{\text {MISRI }}$ cells, few proteins (Cited-2, HIF1 $\alpha$, HSP60, and SIRT2) were overexpressed in donor cells exposed to ${ }^{213} \mathrm{Bi}$-anti-MISRII mAb compared with untreated cells (Supplementary Fig. S7A). Conversely, in recipient cells, additional proteins were induced: ADAMTS1, BCL2, carbonic anhydrase IX, COX-2, DKK-4, FAB-P1, HIF2 $\alpha$, phosphorylated HSP27, indoleamine-pyrrole 2, 3-dioxygenase (IDO), NFK-B, p21, paraoxonase 2 and 3 (PON2, PON3), and SOD2. Conversely, in HCT116 cells, the same proteins were induced in donor cells exposed to ${ }^{125} \mathrm{I}$-antiCEA mAb (Auger RIT) and in recipient cells (nontargeted effect; Supplementary Fig. S7B).

Western blot analysis confirmed the role of oxidative stress, as demonstrated by the increase in phosphorylated NF- $\kappa B$ expression after in vitro Auger and alpha RIT (Fig. 4A; Supplementary Fig. S7C). However, this increase was not confirmed in vivo in tumors collected at 6 hours after alpha-RIT (Fig. 5B).

MBCD and pravastatin reduce RIT efficacy in vivo

Then, to assess the role of lipid rafts in ${ }^{213} \mathrm{Bi}-\mathrm{mAb}$ therapeutic efficacy in vivo, we treated mice harboring intraperitoneal AN3CA cell tumor xenografts with $\mathrm{NaCl}, \mathrm{MBCD}$ alone, ${ }^{213} \mathrm{Bi}$-anti-MISRII $\mathrm{mAb}$ alone, or ${ }^{213} \mathrm{Bi}$-anti-MISRII mAb + MBCD. At day 30 postRIT, tumor mass was significantly reduced in the ${ }^{213} \mathrm{Bi}$-anti-MISRII $\mathrm{mAb}$ group (RIT) compared with the $\mathrm{NaCl}$ group $(P=0.0321$, RIT-treated to untreated tumor mass ratio $=0.02$; Fig. 6A, left). Although not statistically significant, cholesterol levels tended to be lower in MBCD-treated than in NaCl-treated tumors (Fig. 6A, middle). Although MBCD alone was effective in reducing tumor mass and ${ }^{213} \mathrm{Bi}$-anti-MISRII mAb $+\mathrm{MBCD}$ showed a therapeutic efficacy, the combination was less effective than RIT $(P=0.0284$, RIT + MBCD to MBCD tumor mass ratio $=0.05$; Fig. 6A), confirming in vivo the involvement of lipid rafts in alpha RIT therapeutic efficacy. We also observed a similar trend, although not significant, when we used lower activities (12.5 MBq and 7.4 MBq) of ${ }^{213} \mathrm{Bi}$-anti-MISRII mAb (Supplementary Fig. S8), at earlier time point (day 14) post-RIT.

Moreover, the number of 53BP1 foci per cell was lower in tumors from mice harboring A-431 $1_{\text {CEA }}$ tumor cell xenografts after combined treatment with ${ }^{125} \mathrm{I}$-anti-CEA mAb and MBCD compared with ${ }^{125}$ I-anti-CEA mAb alone (Fig. 6A, right).

Similarly, pravastatin modulated Auger RIT efficacy in mice harboring subcutaneous A- $431_{\text {CEA }}$ tumor cell xenografts (Fig. 6B). Compared with the $\mathrm{NaCl}$-treated group, pravastatin delayed tumor growth and increased survival (median survival: 49 vs. 39 days for control; $P=0.17$; Fig. $6 \mathrm{~B}$ ). Survival was comparable in mice treated with ${ }^{125} \mathrm{I}$-anti CEA mAb alone or ${ }^{125} \mathrm{I}$-anti CEA mAb
+ pravastatin (median survival $=55$ vs. 57 days, respectively; $P=0.92$; Fig. 6B). However, at day 39 (at a time where most of the mice were still monitored) or at day 58 (end of the follow-up period), the highest tumor mass reduction ( $\mathrm{NaCl}$ to RIT tumor mass ratio $=0.52$ and 0.71 , respectively) was observed with RIT alone, whereas it was comparable for the pravastatin and pravastatin + RIT groups (pravastatin to pravastatin + RIT tumor mass ratio $=0.5$ and 0.99 , respectively; Fig. $6 \mathrm{C}$ ).

Relative contribution of targeted and nontargeted cytotoxicity in alpha and Auger RIT

Using the present experimental data in donor and recipient cells (Figs. 2 and 4C) and previous data we described for Auger RIT and ${ }^{125}$ I-UdR targeting of the nucleus (34), we could determine the relative contribution of targeted and nontargeted cytotoxicity (Supplementary Methodology and Fig. 7). We found that alpha RIT-targeted cytotoxicity was responsible for $67 \%$ to $94 \%$ of cell death (Fig. 7), and was much higher than the cell death induced by Auger RIT $(<18 \%)$. However, when the emitter was located in the DNA, for instance when using ${ }^{125}$ I-UdR (34), Auger and alpha RIT-targeted effects were similar (i.e., $69.6 \%$ of cell death). Although the nontargeted cytotoxic effects of the ${ }^{212} \mathrm{~Pb}$-anti-HER2 mAb killed only about $7 \%$ of cells, those of the ${ }^{212} \mathrm{~Pb}$-anti-CEA and ${ }^{213} \mathrm{Bi}$-anti-MISRII mAbs caused $30 \%$ to $36 \%$ of cell death (Fig. 7), which means that about $50 \%$ of killing by alpha particles is due to nontargeted effects. We obtained similar nontargeted effect values for Auger RIT using the ${ }^{125} \mathrm{I}$-anti CEA mAb $(28.8 \%)$, indicating that Auger RIT nontargeted effects kill about twice more cells than the corresponding targeted effects.

Moreover, for alpha RIT, lipid rafts contributed significantly to killing and in a similar proportion for targeted and nontargeted cytotoxic effects (Fig. 7), which represents a contribution of about $25 \%$ to $33 \%$ (i.e., $21 \%-24 \%$ of $67 \%-94 \%$ ) of targeted effects and about $50 \%$ of nontargeted effects (i.e., $17.6 \%-20.9 \%$ of $7 \%$ $36 \%)$. For Auger RIT, the contribution of lipid rafts was higher: about $50 \%$ for targeted effects $(9.2 \%-9.4 \%$ of $18 \%)$ and higher $(65 \%-72 \%)$ for nontargeted effects $(18.9 \%-21.6 \%$ of $27 \%-29 \%)$.

\section{Discussion}

In this study, we demonstrated that cell membrane-mediated nontargeted effects play a significant role (up to $50 \%$ depending on situations) during Auger and alpha RIT, and that drugs regulating cholesterol level, such as MBCD, filipin, and statins, could interfere with RIT efficacy.

We first showed in mice bearing small-volume peritoneal carcinomatosis and treated with ${ }^{212} \mathrm{~Pb}$-anti-CEA mAbs that nontargeted effects occur and could limit the negative effect of the antibody distribution heterogeneity by producing similar levels of damage in both irradiated and nonirradiated tumor areas, contributing to the therapeutic efficacy. It must be noted that we showed previously that unlabeled used here antibodies had no therapeutic efficacy under RIT conditions (33). As DNA damage (DNA DSBs) increases proportionally with the irradiation dose (a feature of targeted effects; refs. 36, 37), in the absence of nontargeted signals, the level of DNA lesions in nonirradiated areas should be similar to that measured in $\mathrm{NaCl}$-treated tumors (Fig. 1D)

Conversely, for the ${ }^{212} \mathrm{~Pb}$-anti-HER2 $\mathrm{mAb}$, the relative contribution of targeted effects was higher than that of nontargeted 
A

AN3CA tumor xenografts

A-431 $1_{\text {CEA }}$ tumor xenografts
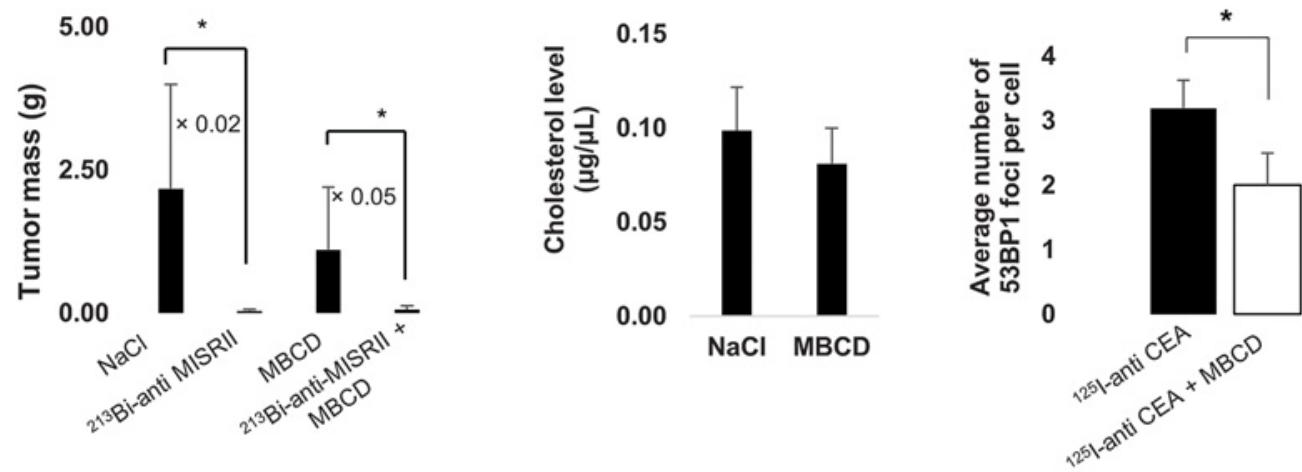

B A-431 $1_{\text {CEA }}$ tumor xenografts
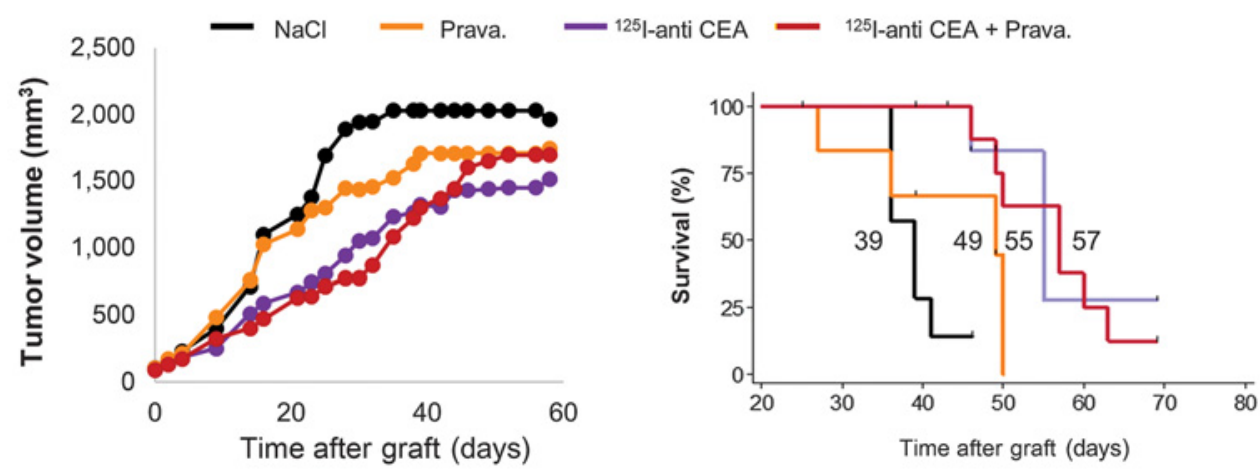

C A-431 $1_{\text {CEA }}$ tumor xenografts

Day 39 after graft

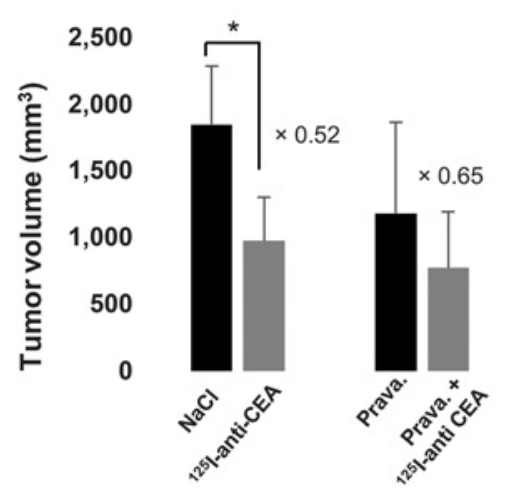

Day 58 after graft

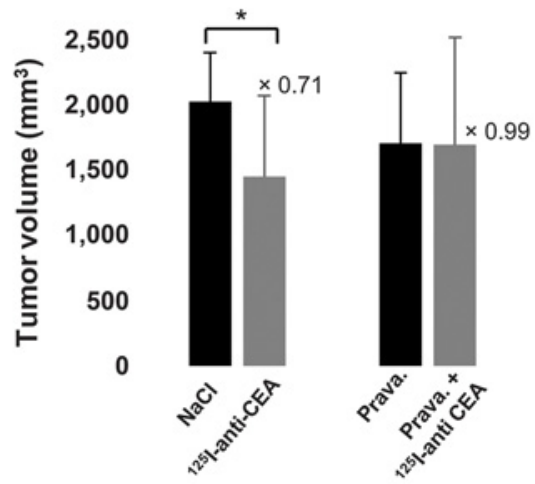

Figure 6.

In vivo effects of drugs that modify cholesterol metabolism on tumor growth, and DNA damage formation. A, Mice bearing i.p. AN3CA tumor cell xenografts were treated with (i) $\mathrm{NaCl}$, (ii) daily i.p. injections of $300 \mathrm{mg} / \mathrm{kg} \mathrm{MBCD}$ from days 7 to 13 after graft, (iii) one injection of $37 \mathrm{MBq}$ of ${ }^{213} \mathrm{Bi}$-anti-MISRII mAb at day 11 , or (iv) both ${ }^{213} \mathrm{Bi}$-anti-MISRII mAb and MBCD. At day 30 after graft, mice were sacrificed, tumors were collected, and the total tumor mass was determined (left). Tumors were also collected in mice ( $n=3$ mice/group) for assessing MBCD effect on the tumor cholesterol level (middle). IHC detection of 53BP1 foci in tumor sections from mice bearing i.p. A-431 $1_{\text {CEA }}$ cell tumor xenografts and killed 24 hours after (i) two injections of 37 MBq of ${ }^{125}$-anti-CEA mAb at days 8 and 11 after graft, or (ii) after daily i.p. injections of MBCD from days 6 to 15 after graft (MBCD) combined with two injections of 37 MBq of ${ }^{125}$-anti-CEA mAb at days 8 and 11 after graft (right). B, Mice bearing subcutaneous A-431 $1_{C E A}$ tumor cell xenografts were treated with (i) $\mathrm{NaCl}$, or (ii) daily i.p. injections of $40 \mathrm{mg} / \mathrm{kg}$ pravastatin from day 10 before graft until day 18 after graft, or (iii) two injections of $37 \mathrm{MBq}$ of ${ }^{125}$-anti-CEA mAb at days 8 and 11 after graft, or (iv) ${ }^{125}$ I-anti-CEA mAb and MBCD. The average tumor volume in each treatment group $(n=8)$ was determined, and Kaplan-Meier survival curves were established. Mice were sacrificed when tumor volume reached $2,000 \mathrm{~mm}^{3}$. C, The ratio between the tumor masses of the indicated groups was calculated. ${ }^{*}, P<0.05$ compared with control animals. 


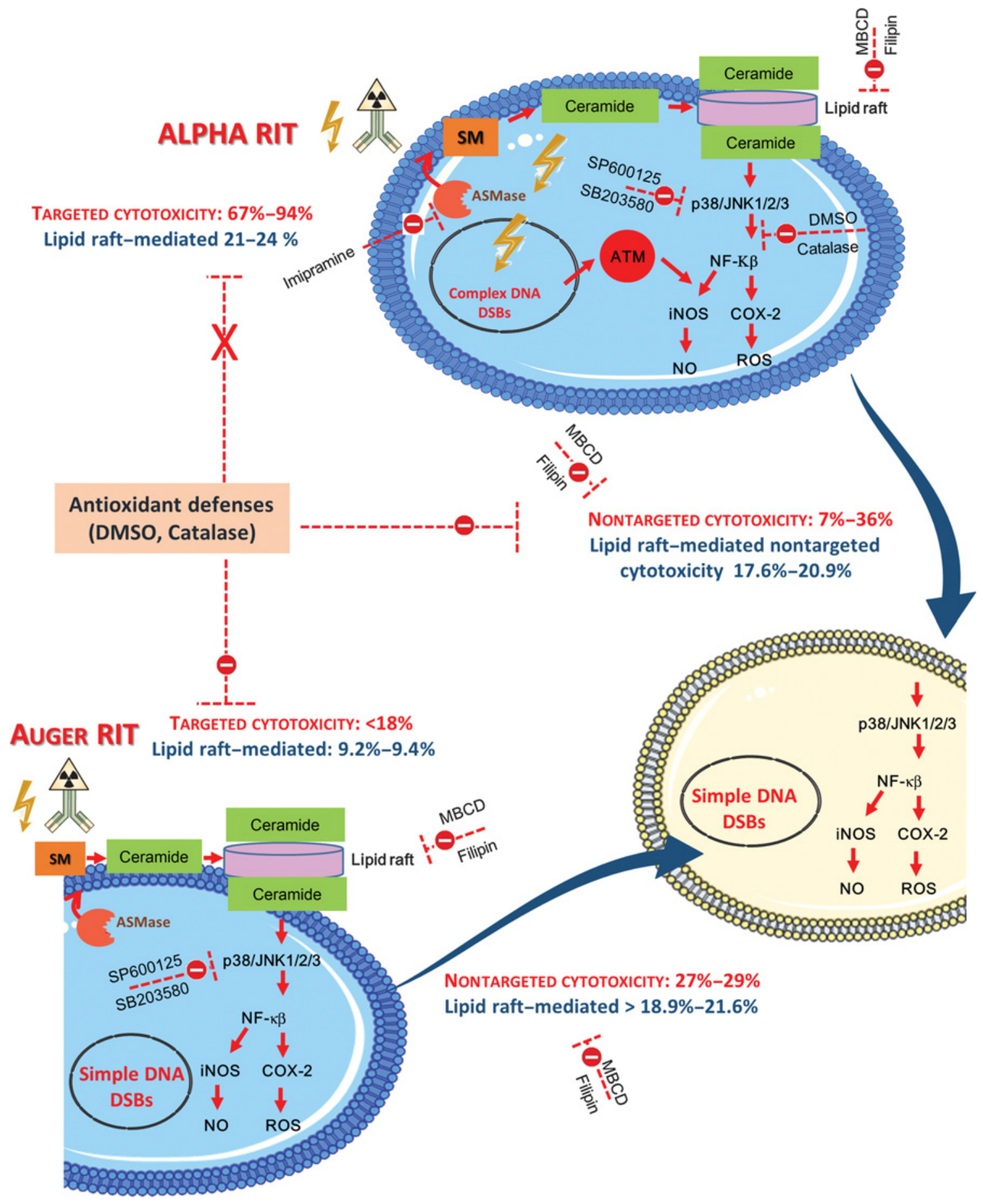

Figure 7.

Contribution of targeted and nontargeted effects during Auger RIT using ${ }^{125} \mathrm{I}-\mathrm{mAbs}$ or alpha RIT using ${ }^{212} \mathrm{~Pb}$ - or ${ }^{213} \mathrm{Bi}$-mAbs. The contribution of targeted and nontargeted effects of RIT with ${ }^{213} \mathrm{Bi}$-anti-MISRII, ${ }^{212} \mathrm{~Pb}$-anti-CEA, ${ }^{212} \mathrm{~Pb}$-anti-HER2, ${ }^{125}$-anti-CEA mAbs, or ${ }^{125} \mathrm{I}$-UdR to cell killing in the presence or not of lipid raft disruptors (filipin, MBCD) or antioxidants (catalase, DMSO, or $\mathrm{N}$-acetyl cysteine) was determined using a Bliss independence mathematical model. Both Auger and alpha RIT activate ASMase through ROS production. ASMase catalyzes sphingomyelin hydrolysis to ceramide and phosphorylcholine, and contributes to the formation of ceramide-enriched domains that activate $\mathrm{p} 38 / \mathrm{JNK} 1 / 2 / 3$, and NF- $\mathrm{KB}$ and downstream signaling pathways. Alpha RIT-targeted effects produced large 53BP1 and $\gamma \mathrm{H} 2 \mathrm{AX}$ foci (assimilated to complex DNA lesions), as indicated by immunofluorescence analysis (see Fig. 1). Conversely, Auger RIT-targeted effects and Auger and alpha RIT-nontargeted effects produced small foci that could represent single DNA lesions. Antioxidant agents reduce the nontargeted effects of both Auger and alpha RIT, but only the targeted effects of Auger RIT. The proportion of cells killed via a lipid raft-mediated process is also indicated. iNOS, inducible nitric oxide synthase; NO, nitric oxide; SM, sphingomyelin. 
effects, and the yield of DNA damage ex vivo was proportional to the dose (36). We then confirmed the nontargeted cytotoxic and genotoxic effects of alpha RIT in vitro using conditioned medium transfer experiments (Fig. 2).

As during RIT the cell membrane is subject to high energy deposition, we hypothesized that it could actively participate in targeted and nontargeted effects. Relatively few studies have investigated the effects of irradiation on the cell membrane $(38,39)$. We found that ceramide production was increased during alpha RIT through ASMase activation (Fig. 3B and C). Ceramide is known to be a second messenger of apoptosis, a cell death process observed during alpha-RIT (Fig. 4C). Moreover, sphingolipids, such as ceramide, interact with each other via hydrophilic interactions between the sphingolipid head groups, and form complexes that are stabilized by cholesterol that fills the gaps between large sphingolipid molecules. These complexes constitute very small floating domains in the membrane (called lipid rafts) that are in a liquid ordered phase and are insoluble in cold nonionic detergents $(40,41)$. We confirmed the formation of lipid raft during alpha-RIT (Fig. 3A) which corroborated a previous study showing also their formation during Auger RIT (34). Upon irradiation, ceramide production leads to aggregation of lipid raft domains that are converted into larger membrane platforms. These platforms represent lateral subcompartments that participate in the segregation of molecules and the reorganization of receptor molecules, membrane signaling, and trafficking. Ceramide also interacts and activates the serine/threonine phosphatases PP2A and PP1 that in turn act on different signaling proteins, including MAPKs (AKT, c-JUN), PKC isoforms (PKC $\alpha$ and $\zeta$ ), kinase suppressor of Ras (KSR), pRB, and BCL-2 (8, 42 44). Here, we found that $\mathrm{p} 38$ and JNK $1 / 2 / 3$ are activated during alpha RIT and play a significant role in targeted and nontargeted effects in vitro (Figs. $3 \mathrm{~F}, 4$, and $5 \mathrm{~A}$ ) and in vivo (Fig. 5B). However, phosphorylation of $\mathrm{p} 38$ and JNK1/2/3 was lost, and clonogenic cell survival was increased when cell cultures and mice bearing tumor cell xenografts were treated with the combination of alpha RIT and MBCD (and also filipin in vitro), a drug that disrupts lipid rafts by cholesterol depletion (Fig. 5A and B).

We showed that MBCD and filipin reduced the efficacy of alpha-RIT in vitro (Fig. 3D) and also in vivo (Fig. 6A; Supplementary Fig. S8). In vivo, DNA damage level (53BP1 foci) was reduced in tumors of mice treated with RIT + MBCD. Similarly, Auger RIT efficacy was decreased when performed in the presence of pravastatin, an inhibitor of hydroxymethylglutaryl-CoA reductase (involved in cholesterol synthesis) and also of lowdensity lipoprotein synthesis. This result is important because older patients undergoing alpha RIT are often also treated for hypercholesterolemia.

Moreover, our results suggest a role for ROS during alphaRIT (Fig. 4A; Supplementary Fig. S7). Besides producing DNA lesions (45), $\mathrm{HO}^{\circ}$ could participate in the oxidation of cysteine 629 in ASMase C-terminus, leading to ASMase activation (46-48).

We showed that catalase and DMSO limited the nontargeted and also targeted (to a lower extent) cytotoxic effects of alpha RIT (Fig. 5C) and also reduced the level of p-p38, p-JNK1/2/3, and $\mathrm{p}-\mathrm{NF}-\mathrm{\kappa B}$ in vitro (Fig. $4 \mathrm{~A}$ ). We did not observe any change in p-NF- $\mathrm{KB}$ level in tumors (Fig. 5B). However, overall, p-NF$\kappa \mathrm{B}$ expression was very low and was not correlated with any treatment. It would be of interest in further experiments to use NF- $\mathrm{BB}$ knockout mice to better delineate the role of the latter transcription factor in vivo. In recipient cells, ROS production could lead to simple DNA DSBs that recruit a lower number of DNA repair proteins, as shown by the presence of small 53BP1 and $\gamma \mathrm{H} 2 \mathrm{AX}$ foci only. Conversely, ROS seems to be less implicated in alpha RIT-targeted effects that generate dense DNA ionization, leading to more complex lesions and the recruitment of a higher number of DNA repair proteins, as suggested by the larger 53BP1 and $\gamma \mathrm{H} 2 \mathrm{AX}$ foci (Fig. 2C and D).

Therefore, these results indicate that Auger and alpha RIT, which have been described as potential therapeutic tools mainly dedicated to the treatment of microscopic diseases, can also be efficient for small volume (several $\mathrm{mm}$ in size) tumors, far beyond the expected range of Auger and alpha particles. This is also relevant for radionuclide therapy in which radiolabeled vectors cannot gain access to all tumor cells. Nontargeted effects could thus contribute to the observed therapeutic efficacy of the new radiopharmaceuticals currently under evaluation $(49,50)$.

Finally, it must be noted that nontargeted effects of radiation might also include abscopal and systemic effects that are measured at a distance from the irradiated tumor area and that are mediated by the immune system $(51,52)$. Although these effects have been poorly studied during RIT, they might contribute to RIT effectiveness and require the development of dedicated immunocompetent preclinical models (53).

This study showed that alpha RIT is mediated by targeted and nontargeted effects. Depending on the radiopharmaceuticals, nontargeted effects contribution can be high. Upon radiolabeled $\mathrm{mAb}$ binding to cell surface receptors, the formation of ceramideenriched large platforms and the subsequent activation of $\mathrm{p} 38$ and JNK-mediated signaling pathways are partly responsible for the nontargeted effects and, to a lower extent, for targeted effects. As targeted effects are dose-related but not nontargeted effects, these results have consequences on the planning and prediction of the therapeutic efficacy and side effects of TRT using alpha particles. Moreover, they suggest that patients undergoing treatment to modify lipid metabolism could respond differently to TRT.

\section{Disclosure of Potential Conflicts of Interest}

No potential conflicts of interest were disclosed.

\section{Authors' Contributions}

Conception and design: R. Ladjohounlou, A. Pichard, V. Boudousq, S. Paillas, F. Bruchertseifer, I. Navarro-Teulon, J.-P. Pouget

Development of methodology: R. Ladjohounlou, A. Pichard, E. Deshayes, V. Boudousq, M. Bardiès, F. Bruchertseifer, A. Morgenstern, J. Torgue

Acquisition of data (provided animals, acquired and managed patients, provided facilities, etc.): R. Ladjohounlou, C. Lozza, A. Pichard, J. Constanzo, J. Karam, P. Le Fur, E. Deshayes, M. Busson, F. Bruchertseifer, I. Navarro-Teulon, J-P. Pouget

Analysis and interpretation of data (e.g., statistical analysis, biostatistics, computational analysis): R. Ladjohounlou, J. Constanzo, J. Karam, E. Deshayes, M. Jarlier, S. Marcatili, M. Bardiès, J.-P. Pouget

Writing, review, and/or revision of the manuscript: R. Ladjohounlou, C. Lozza, J. Constanzo, S. Paillas, A. Morgenstern, J.-P. Pouget

Administrative, technical, or material support (i.e., reporting or organizing data, constructing databases): R. Ladjohounlou, C. Lozza, M. Le Blay, F. Bruchertseifer, A. Morgenstern

Study supervision: R. Ladjohounlou, S. Paillas, J.-P. Pouget 


\section{Acknowledgments}

This work was financed by ORANO Med LLC, SIRIC Montpellier Cancer Grant INCa_Inserm_DGOS_12553, Ligue Nationale Contre le Cancer Electricité de France Comité de Radioprotection, Action Nu1.1 of Plan Cancer 2009-2103 (ASC 13038FSA), and French National Research Agency as part of the Investissements d'Avenir program (ANR-10-LABX-53-01).

\section{References}

1. Zalutsky MR, Reardon DA, Akabani G, Coleman RE, Friedman AH, Friedman HS, et al. Clinical experience with alpha-particle emitting 211At: treatment of recurrent brain tumor patients with 211At-labeled chimeric antitenascin monoclonal antibody 81C6. J Nucl Med 2008;49: $30-8$.

2. Andersson H, Cederkrantz E, BackT, Divgi C, Elgqvist J, Himmelman J, et al Intraperitoneal alpha-particle radioimmunotherapy of ovarian cancer patients: pharmacokinetics and dosimetry of (211)At-MX35 F(ab')2-a phase I study. J Nucl Med 2009;50:1153-60.

3. Parker C, Nilsson S, Heinrich D, Helle SI, O'Sullivan JM, Fossa SD, et al Alpha emitter radium-223 and survival in metastatic prostate cancer. N Engl J Med 2013;369:213-23.

4. Strosberg J, El-Haddad G, Wolin E, Hendifar A, Yao J, Chasen B, et al. Phase 3 trial of (177)Lu-Dotatate for midgut neuroendocrine tumors. N Engl J Med 2017:376:125-35.

5. Kratochwil C, Bruchertseifer F, Rathke H, Bronzel M, Apostolidis C, Weichert W, et al. Targeted alpha-therapy of metastatic castration-resistant prostate cancer with (225)Ac-PSMA-617: dosimetry estimate and empiric dose finding. J Nucl Med 2017;58:1624-31.

6. Krolicki L, Bruchertseifer F, Kunikowska J, Koziara H, Krolicki B, Jakucinski $\mathrm{M}$, et al. Prolonged survival in secondary glioblastoma following local injection of targeted alpha therapy with (213)Bi-substance P analogue. Eur J Nucl Med Mol Imaging 2018;45:1636-44.

7. Pouget JP, Navarro-Teulon I, Bardies M, Chouin N, Cartron G, Pelegrin A et al. Clinical radioimmunotherapy-the role of radiobiology. Nat Rev Clin Oncol 2011;8:720-34.

8. Corre I, Guillonneau M, Paris F. Membrane signaling induced by high doses of ionizing radiation in the endothelial compartment. Relevance in radiation toxicity. Int J Mol Sci 2013;14:22678-96.

9. Stark G. The effect of ionizing radiation on lipid membranes. Biochim Biophys Acta 1991;1071:103-22.

10. Negre-Salvayre A, Coatrieux C, Ingueneau C, Salvayre R. Advanced lipid peroxidation end products in oxidative damage to proteins. Potential role in diseases and therapeutic prospects for the inhibitors. Br J Pharmacol 2008; 153:6-20.

11. Garcia-Barros M, Paris F, Cordon-Cardo C, Lyden D, Rafii S, HaimovitzFriedman A, et al. Tumor response to radiotherapy regulated by endothelial cell apoptosis. Science 2003;300:1155-9.

12. Kolesnick R, Fuks Z. Radiation and ceramide-induced apoptosis. Oncogene 2003;22:5897-906.

13. Pouget JP, Georgakilas AG, Ravanat JL. Targeted and off-target (Bystander and Abscopal) effects of radiation therapy: redox mechanisms and risk/ benefit analysis. Antioxid Redox Signal 2018;29:1447-87.

14. Gulbins E, Kolesnick R. Raft ceramide in molecular medicine. Oncogene 2003:22:7070-7.

15. Nagasawa H, Cremesti A, Kolesnick R, Kolesnick R, Fuks Z, Little JB Involvement of membrane signaling in the bystander effect in irradiated cells. Cancer Res 2002;62:2531-4.

16. Lyng FM, Maguire P, McClean B, Seymour CB, Mothersill C. The involvement of calcium and MAP kinase signaling pathways in the production of radiation-induced bystander effects. Radiat Res 2006;165:400-9.

17. Azzam EI, de Toledo SM, Gooding T, Little JB. Intercellular communication is involved in the bystander regulation of gene expression in human cells exposed to very low fluences of alpha particles. Radiat Res 1998;150: 497-504

18. Azzam EI, de Toledo SM, Little JB. Oxidative metabolism, gap junctions and the ionizing radiation-induced bystander effect. Oncogene 2003;22: 7050-7.

19. Lyng FM, Seymour CB, Mothersill C. Initiation of apoptosis in cells exposed to medium from the progeny of irradiated cells: a possible mechanism for bystander-induced genomic instability? Radiat Res 2002;157:365-70.
20. Huo L, Nagasawa H, Little JB. HPRT mutants induced in bystander cells by very low fluences of alpha particles result primarily from point mutations. Radiat Res 2001;156:521-5

21. Belyakov OV, Folkard M, Mothersill C, Prise KM, Michael BD. Bystanderinduced differentiation: a major response to targeted irradiation of a urothelial explant model. Mutat Res 2006;597:43-9.

22. Azzam EI, Raaphorst GP, Mitchel RE. Radiation-induced adaptive response for protection against micronucleus formation and neoplastic transformation in C3H 10T1/2 mouse embryo cells. Radiat Res 1994;138:S28-31

23. Poleszczuk J, Krzywon A, Forys U, Widel M. Connecting radiation-induced bystander effects and senescence to improve radiation response prediction. Radiat Res 2015;183:571-7.

24. Morgan WF. Is there a common mechanism underlying genomic instability, bystander effects and other nontargeted effects of exposure to ionizing radiation? Oncogene 2003;22:7094-9.

25. Morgan WF. Non-targeted and delayed effects of exposure to ionizing radiation: II. Radiation-induced genomic instability and bystander effects in vivo, clastogenic factors and transgenerational effects. Radiat Res 2003 159:581-96

26. Morgan WF. Non-targeted and delayed effects of exposure to ionizing radiation: I. Radiation-induced genomic instability and bystander effects in vitro. Radiat Res 2003;159:567-80

27. Mothersill C, Seymour CB. Radiation-induced bystander effects-implications for cancer. Nat Rev Cancer 2004;4:158-64

28. Vallis KA, Reilly RM, Scollard D, Merante P, Brade A, Velauthapillai S, et al Phase I trial to evaluate the tumor and normal tissue uptake, radiation dosimetry and safety of (111)In-DTPA-human epidermal growth factor in patients with metastatic EGFR-positive breast cancer. Am J Nucl Med Mol Imaging 2014;4:181-92

29. Santoro L, Boutaleb S, Garambois V, Bascoul-Mollevi C, Boudousq V Kotzki PO, et al. Noninternalizing monoclonal antibodies are suitable candidates for 125I radioimmunotherapy of small-volume peritoneal carcinomatosis. J Nucl Med 2009;50:2033-41.

30. Hallqvist A, Bergmark K, BackTA, Andersson H, Dahm-Kahler P, Johansson $\mathrm{M}$, et al. Intraperitoneal alpha-emitting radio immunotherapy with Astatine-211 in relapsed ovarian cancer; long-term follow-up with individua absorbed dose estimations. I Nucl Med 2019 Jan 25. [Epub ahead of print].

31. Deshayes E, Ladjohounlou R, Le Fur P, Pichard A, Lozza C, Boudousq V, et al. Anti-MISRII radiolabeled antibodies: new tools for a theranostic approach in ovarian cancer. J Nucl Med 2018;59:1234-42.

32. Kohler G, Howe SC, Milstein C. Fusion between immunoglobulin-secreting and nonsecreting myeloma cell lines. Eur J Immunol 1976;6:292-5.

33. Boudousq V, Bobyk L, Busson M, Garambois V, Jarlier M, Charalambatou $\mathrm{P}$, et al. Comparison between internalizing anti-HER2 mAbs and noninternalizing anti-CEA mAbs in alpha-radioimmunotherapy of small volume peritoneal carcinomatosis using 212Pb. PLoS One 2013;8:e69613.

34. Paillas S, Ladjohounlou R, Lozza C, Pichard A, Boudousq V, Jarlier M, et al Localized irradiation of cell membrane by Auger electrons is cytotoxic through oxidative stress-mediated nontargeted effects. Antioxid Redox Signal 2016;25:467-84.

35. Pouget JP, Santoro L, Raymond L, Chouin N, Bardies M, Bascoul-Mollevi C, et al. Cell membrane is a more sensitive target than cytoplasm to dense ionization produced by auger electrons. Radiat Res 2008;170:192-200.

36. Rothkamm K, Lobrich M.Evidence for a lack of DNA double-strand break repair in human cells exposed to very low x-ray doses. Proc Natl Acad Sci U S A 2003;100:5057-62.

37. Goodhead DT. Initial events in the cellular effects of ionizing radiations: clustered damage in DNA. Int J Radiat Biol 1994;65:7-17.

38. Haimovitz-Friedman A, Kan CC, Ehleiter D, Persaud RS, McLoughlin M Fuks $\mathrm{Z}$, et al. Ionizing radiation acts on cellular membranes to generate ceramide and initiate apoptosis. J Exp Med 1994;180:525-35. 
39. Catala A. Lipid peroxidation of membrane phospholipids generates hydroxy-alkenals and oxidized phospholipids active in physiological and/or pathological conditions. Chem Phys Lipids 2009;157:1-11.

40. Simons K, Ikonen E. Functional rafts in cell membranes. Nature 1997;387: 569-72.

41. Brown DA, London E. Functions of lipid rafts in biological membranes. Annu Rev Cell Dev Biol 1998;14:111-36.

42. Chalfant CE, Kishikawa K, Mumby MC, Kamibayashi C, Bielawska A Hannun YA. Long chain ceramides activate protein phosphatase-1 and protein phosphatase-2A. Activation is stereospecific and regulated by phosphatidic acid. J Biol Chem 1999;274:20313-7.

43. Bourbon NA, Yun J, Kester M. Ceramide directly activates protein kinase C zeta to regulate a stress-activated protein kinase signaling complex. J Biol Chem 2000;275:35617-23.

44. Zhang Y, Yao B, Delikat S, Bayoumy S, Lin XH, Basu S, et al. Kinase suppressor of Ras is ceramide-activated protein kinase. Cell 1997;89: 63-72.

45. Cadet J, Delatour T, Douki T, Gasparutto D, Pouget JP, Ravanat JL, et al. Hydroxyl radicals and DNA base damage. Mutat Res 1999;424:9-21.

46. Qiu H, Edmunds T, Baker-Malcolm J, Karey KP, Estes S, Schwarz C, et al. Activation of human acid sphingomyelinase through modification or deletion of C-terminal cysteine. J Biol Chem 2003;278 32744-52.
47. Santana P, Pena LA, Haimovitz-Friedman A, Martin S, Green D, McLoughlin $\mathrm{M}$, et al. Acid sphingomyelinase-deficient human lymphoblasts and mice are defective in radiation-induced apoptosis. Cell 1996;86:189-99.

48. Castillo SS, Levy M, Thaikoottathil JV, Goldkorn T. Reactive nitrogen and oxygen species activate different sphingomyelinases to induce apoptosis in airway epithelial cells. Exp Cell Res 2007;313:2680-6.

49. Sathekge M, Bruchertseifer F, Knoesen O, Reyneke F, Lawal I, Lengana T, et al. (225)Ac-PSMA-617 in chemotherapy-naive patients with advanced prostate cancer: a pilot study. Eur J Nucl Med Mol Imaging 2019;46: 129-38.

50. Morgenstern A, Apostolidis C, Kratochwil C, Sathekge M, Krolicki L Bruchertseifer F. An overview of targeted alpha therapy with (225)Actinium and (213)Bismuth. Curr Radiopharm 2018;11:200-8.

51. Tubin S, Popper HH, Brcic L. Novel stereotactic body radiation therapy (SBRT)-based partial tumor irradiation targeting hypoxic segment of bulky tumors (SBRT-PATHY): improvement of the radiotherapy outcome by exploiting the bystander and abscopal effects. Radiat Oncol 2019;14:21.

52. Demaria S, Ng B, Devitt ML, Babb JS, Kawashima N, Liebes L, et al. Ionizing radiation inhibition of distant untreated tumors (abscopal effect) is immune mediated. Int J Radiat Oncol Biol Phys 2004;58:862-70.

53. Gorin JB, Menager J, Gouard S, Maurel C, Guilloux Y, Faivre-Chauvet A, et al. Antitumor immunity induced after alpha irradiation. Neoplasia 2014;16:319-28. 


\section{Clinical Cancer Research}

\section{Drugs That Modify Cholesterol Metabolism Alter the p38/JNK-Mediated Targeted and Nontargeted Response to Alpha and Auger Radioimmunotherapy}

Riad Ladjohounlou, Catherine Lozza, Alexandre Pichard, et al.

Clin Cancer Res 2019;25:4775-4790. Published OnlineFirst May 6, 2019.

\section{Updated version Access the most recent version of this article at: doi:10.1158/1078-0432.CCR-18-3295}

Supplementary Access the most recent supplemental material at:

Material http://clincancerres.aacrjournals.org/content/suppl/2019/05/04/1078-0432.CCR-18-3295.DC1

Cited articles This article cites 52 articles, 12 of which you can access for free at: http://clincancerres. aacrjournals.org/content/25/15/4775. full\#ref-list-1

E-mail alerts Sign up to receive free email-alerts related to this article or journal.

Reprints and To order reprints of this article or to subscribe to the journal, contact the AACR Publications Department at Subscriptions pubs@aacr.org.

Permissions To request permission to re-use all or part of this article, use this link http://clincancerres.aacrjournals.org/content/25/15/4775.

Click on "Request Permissions" which will take you to the Copyright Clearance Center's (CCC) Rightslink site. 